\title{
Networks and Productivity: Causal Evidence from Editor Rotations*
}

\author{
J onathan Brogaard \\ J oseph Engelberg \\ Christopher A. Parsons
}

First Draft: October 2011

Current Draft: March 2012

\begin{abstract}
Using detailed publication and citation data for over 50,000 articles from 30 major economics and finance journals, we investigate whether network proximity to an editor influences research productivity. During an editor's tenure, his current university colleagues publish about $100 \%$ more papers in the editor's journal, compared to years when he was not editor. In contrast to editorial nepotism, such "inside" articles have significantly higher ex post citation counts, even when same-journal and self-cites are excluded. Our results thus suggest that despite potential conflicts of interest faced by editors, personal associations are used to improve selection decisions.
\end{abstract}

* We have benefited from discussions with Kenneth Ahern, Malcolm Baker, Jay Hartzell, Han Kim, Richard Ruback, J eremy Stein, Paul Tetlock, Allan Timmerman, Sheridan Titman, and especially Adolfo de Motta. We also thank seminar participants at Harvard, UCSD Economics, Florida State, New York University, University of Oklahoma, UC Riverside, Penn State and the University of Washington.

Contact: Jonathan Brogaard, Foster School of Business, University of Washington, (Email) brogaard@uw.edu , (Tel) 206-685-7822; J oseph Engelberg, University of California - San Diego, Rady School of Management, (Email) jengelberg@ucsd.edu (Tel) 858-822-7912; and Christopher Parsons, University of California - San Diego, Rady School of Management, (Email) caparsons@ucsd.edu (Tel) 919-265-9246. 


\section{Introduction}

Networks are of first order importance in many economic decisions and outcomes. Whether finding a job (Granovetter, 1974) or surviving a POW camp (Costa and Kahn, 2007), it is clear that networks funnel resources to benefit their members. Less obvious is whether such benefits arise via efficiency improvements, or whether they simply reflect value transfers from those outside the network. The key hurdle is that in most cases, the econometrician cannot benchmark the choices made by network members (e.g., which people are recommended for jobs) to an objective quality standard (i.e., which people should have been recommended).

In this paper, we study a setting largely immune from this criticism: academic publishing. Although a journal editor may derive personal benefit by imposing a lower quality standard on his co-authors or colleagues, an article's ultimate success is determined less subjectively. Thus, by comparing the observed choices of editors (which papers are published) to the market's ex post judgment of article quality (which papers are most cited), we can ask whether the collective behavior of editors coincides with private or broader objectives.

Our analysis covers over 50,000 articles published in 30 top economics (e.g., American Economic Review) and finance journals (e.g., J ournal of Finance) since 1955. We begin by first collecting the editor or editor(s) for each journal, and then, using the affiliations of each, analyze the publishing patterns of their university colleagues. Our main interest is whether an editor's university colleagues have better success publishing in the editor's own journal, during the specific years he is editor. With a sample of such "inside" articles, we compare their citation performance to other articles published in the same journal, and during the same year. It is this comparison that allows us to infer whether editors use information advantages to improve selection decisions, or whether they bow to conflicts of interest.

The design of our empirical tests is important for appreciating how the effects are identified. For each university i in our data set, we aggregate into a single observation the number of articles published in journal $\mathrm{j}$ at time t. As an example, the number of Econometrica 
articles published by Harvard faculty in 1997 would constitute a single observation. The main explanatory variable is an editorial-match dummy variable that takes a value of one if, and only if, the editor of journal $\mathrm{j}$ two years prior (t-2) worked at institution $\mathrm{i}^{1}{ }^{1}$ Continuing with the example above, because Econometrica did not have an editor from Harvard in 1995, the match variable would take a value of zero. However, because Harvard's Drew Fudenberg became an Econometrica editor in 1996, Harvard faculty's Econometrica publications in 1998 would now be associated with an editorial match - i.e., the dummy variable would equal one.

The types of event described above - whereby one editor replaces another - have dramatic effects on the publication rates of their respective institutions. Continuing with the example above, our tests effectively divide Harvard's history since 1955 into two mutually exclusive periods: 1) those when it had an editor at Econometrica (1969-1977, 1989-1992, 19961999, and 2009-2011), and, 2) those when it did not (1955-1968, 1978-1988, 1993-1995, 20002008)..$^{2}$ Averaged across all observations, we find that editorial matching years are associated with about $100 \%$ more publications at the journal of interest, compared to non-matching years. Statistically, this difference is highly significant.

The structure of the data allows us to be precise about a causal link between editors and the publication rates of their colleagues. First, recalling that our unit of observation is a schooljournal-year triple, we can include fixed effects for every pairwise combination of these, i.e., dummy variables for each school-year, journal-year, and school-journal pairing. The first of these accounts for time varying school quality, such as Harvard's aggregate output change since 1955, and allays concerns that editors are selected from improving departments. The second controls for size differences across journals, which for example, accounts for Econometrica publishing fewer articles per year than the American Economic Review. The final interaction

\footnotetext{
1 The results are not particularly sensitive to a 2-year time lag. While this is probably reasonable over the entire time period, we present our results with both 1- and 3-year lags, as well as lags that change through time (e.g., shorter lags in the 1950s-1970s, and longer lags in recent decades).

${ }^{2}$ Harvard's Econometrica editors are Griliches (1969-1977), Mas-Colell (1989-1992), Fudenberg (19961999), and Stock (2009-present).
} 
addresses any persistent school-journal match effects, which might occur if institutions persistently specialize in certain fields. For example, perhaps Harvard places special, persistent emphasis on game theory or econometric theory. The $100 \%$ marginal effect reported above is averaged across journal-school-year observations, and is net of all three sets of school-year, school-journal, and journal-year fixed effects.

A problem remains, however, if institutional specialization is not constant, and is correlated with editorial appointments. For example, perhaps Drew Fudenberg's appointment to Econometrica coincides with Harvard having a temporary emphasis on game theory or econometrics. (The fact that Harvard had four distinct Econometrica editorships since 1955 makes this less plausible, but serves to make the general point.) Although the dummy trap precludes the inclusion of school-journal-year fixed effects in our regressions, we can come close. Instead of soaking up unobserved heterogeneity with the three pair-wise sets of fixed effects, we include in the regressions several "false" editorial appointments, corresponding to the years immediately before and immediately after an editor's appointment. The main advantage is that like the unit of observation, such false editorial matches are defined at the journal-school-year triple, but differ from the genuine matches by only a year or two in either direction.

For example, rather than matching up Harvard's Econometrica publications in 1988 with Fudenberg's actual first year as editor in 1996, we would apply false matches to HarvardEconometrica in years 1995 or 1994, which, respectively, are one and two years before Fudenberg arrived. Here, the idea is that if Fudenberg's appointment is correlated with some Harvard-specific improvement in econometric research, this should be closely approximated by Harvard's Econometrica output one or two years prior. The same reasoning applies on the back end of his tenure, after 1999.

This exercise changes virtually nothing. Although there is a slight increase in a school's baseline productivity leading up to an editor's appointment, and some mild persistence after he 
is gone, the vast majority of the action is during the exact years an editor is in residence. Figure 1 shows this graphically, averaged across all journals. This almost step-like pattern is nearly impossible to square with time-varying changes in institutional specialties, and moreover, suggests few, if any, lasting productivity improvements after an editor's stint commences.

While these results are indicative of editors having a causal influence on their colleagues' productivity, they do not identify the mechanism. There are three main possibilities. First, editors may simply favor their colleagues by publishing lower quality papers. Second, it is possible that editors simply have better information about papers authored by their colleagues, and consequently, are in a better position to evaluate them. Finally, perhaps journals confer location externalities (e.g., hosting conferences associated with the journal, increasing the faculty's visibility, generating enthusiasm, etc.). In the latter case, it is not so much that editors are better informed about their colleagues (although they may be), but that housing a journal cause faculty to be, temporarily at least, more productive.

It is relatively simple to rule out nepotism, so we discuss this first. If editors are passing over higher quality papers in order to publish their colleagues' work, this will be detectible in ex post citation counts. Here, the relative comparison is between citations for articles written by an editor's colleagues, and all other articles published in that same journal-year. To continue with the example above, we want to compare citation counts for Econometrica articles published in 1999 by Harvard faculty (tracing back to Fudenberg's editorship in 1997), to Econometrica articles published in 1999 by non-Harvard faculty. Of course, even this comparison isn't entirely fair, because Harvard's typical Econometrica paper may be of different average quality than an Econometrica paper written by faculty at a different school. So, like with the output regressions, we also include school-year (e.g., Harvard-1999), school-journal (e.g., Harvard-Econometrica), and journal-year (e.g., Econometrica-1999) fixed effects.

Regardless of the specification - some of which even include dummy variables for individual authors - the results indicate that when an editor publishes a colleague's paper, it is 
invariably of higher average quality. The size of this effect varies somewhat depending on the specification, but is consistently in the neighborhood of $10-20 \%$. Virtually none of this effect is due to self- or same-journal citations, suggesting almost no (successful at least) attempts by editors to rig citation counts to favor their colleagues ex post. ${ }^{3}$

The distinction between the second and third possibilities is more tenuous. To see why, note that if a journal temporarily makes the editor's faculty more productive, this could easily manifest in both output and citation counts. Likewise, even if an editor's colleagues write the exact same papers, a better informed editor might be able to spot "diamonds in the rough" papers too risky for an uninformed editor to publish, but attractive for editors well equipped to evaluate them. ${ }^{4}$ Because either mechanism is capable of reconciling both higher output and higher citation counts, we have to look at other patterns.

Two pieces of evidence provide support against journals conferring productivity externalities, and consequently, point to the informed-editor hypothesis. First, as Figure 1 makes clear, virtually all the output reduction is realized in the year directly following an editor's departure. If journal-generated enthusiasm or visibility were at work, it seems more likely that these effects should attenuate more slowly, if at all, particularly in the case of visibility. Second, the fact that we observe increased output only at the editor's journal is hard to explain with more enthusiastic or well-known colleagues. For example, if Drew Fudenberg's Econometrica appointment in 1996 made Harvard's faculty more productive generally, we should see spikes not only in Econometrica beginning in 1998, but presumably also in Journal of Political Economy or American Economic Review. Yet instead, we find relatively flat output at these control journals, but steeply increasing spikes at the home journal upon an editor's appointment, followed by equally precipitous declines upon his departure.

\footnotetext{
${ }^{3}$ We obtain similar results if we examine the citation counts of an editor's past co-authors, in addition to his colleagues. While interesting, and useful for providing confirmation of the same result for an editor's colleagues, we are most interested in tying together the output results and citation results, and the former are easily observable only for an editor's colleagues.

${ }^{4}$ See Section 4c for a stylized model that illustrates this intuition.
} 
Our results pertain to the growing literature on networks and economic outcomes, and specifically, on the potential for in-group favoritism to outweigh the benefits of network externalities. See Banerjee and Munshi (2004), Jackson and Schneider (2011), and Fisman, Paravasini, and Vig (2011) for recent examples. It also builds upon the seminal work of Laband and Piette (1994), which examines citation counts for an editor's co-authors in the 1984-1985 cross-section. Relative to their work, we contribute not only by examining research output, but also by identifying editorial effects from the time-series. As discussed in the text, trends in institutional quality are likely to be correlated with editor selection, making time series changes in editorship attractive for identification, both for research output and citations.

The paper is organized as follows. In Section II, we describe our data and the construction of variables. Section III presents the results of our main specifications relating publication frequency to the presence or absence of a connected editor. Section IV explores why an editor's university colleagues might have better success publishing during the editor's tenure. Section V includes a number of robustness and specification checks, and Section VI concludes.

\section{Data and Variable Construction}

We collected publication, citation, and editorship data for 30 leading economics and finance journals. Our set includes general economics journals (e.g., Quarterly Journal of Economics (QJ E), J ournal of Political Economy, Econometrica, Review of Economic Studies, and American Economic Review (AER)). It also includes top field journals in finance (e.g., J ournal of Finance, Review of Financial Studies, Journal of Financial Economics), urban economics (e.g., Journal of Urban Economics), econometrics (e.g., J ournal of Econometrics), labor (e.g., J ournal of Labor Economics), game theory (e.g., Games and Economic Behavior), and monetary economics (e.g., J ournal of Monetary Economics). The complete list of journals is presented in Table 1. As Row 1 of Table 2 shows, the typical journal in our set publishes a 
little more than 47 articles every year, although this varies substantially, with an interquartile range of 29-59.

In order to build a database of historical editorships and their affiliations, we searched the JSTOR and ScienceDirect databases, which contain PDF versions of historical issues for each journal. Usually, the editor and co-editors are named in the first few pages, or front matter, of each journal issue. In a few cases, names were either not legible or were not listed, so we obtained physical copies from local libraries. When these two options failed, we filled in the blanks from CVs, obituaries, biographies, and in some instances, personal correspondence.

There is some variability across journals in how editors are listed. While some journals list a single editor (e.g., currently William Schwert at the J ournal of Financial Economics), others have a flatter hierarchy (e.g., the Quarterly J ournal of Economics, which currently lists four editors of equivalent standing). Other arrangements are observed as well, such as the Journal of Finance, which in 2011 lists Campbell Harvey as "Editor" and J ohn Graham as "CoEditor." Because of this variability, some subjectivity is required, although in most cases the distinction between editors and associate editors is clear. As shown in the second and third Rows of Table 2, journals in our sample have three to four editors per year on average, and the typical editor serves for about six years. Also shown (Row 4) is the number of people editors have historically co-authored with (average 12.6) in years leading up to their editorships.

Next, we used Web of Science (WOS) to gather detailed publication records. For every economics journal since 1955 (not just the 30 for which we collect editor histories), ${ }^{5}$ we downloaded the "full record" which includes the number of authors (which Table 2, Row 5

\footnotetext{
${ }^{5}$ Using the entire database (224 economics journals) from WOS, rather than the 30 journals on our list, has several advantages. First, we can use all 224 economics journals to observe co-author relationships between editors and authors. This allows us to reduce Type II errors (failing to observe true relationships), because we observe a wide spectrum of economics publications and, hence, co-authorships. We can also use the other journals to more accurately measure the publication and citation history of individual authors. This is important for our citation analysis, where historical citation counts are, as we will see, an excellent measure of author quality. Finally, because we observe the cited references of every economics publication, we know precisely which economics articles cite each other. This helps us deal with potential problems stemming from same-journal citations and self-citations.
} 
shows to be 1.66 on average), school affiliation(s), publication year, journal issue and page numbers, a list of articles the publication cited, and the number of times the publication is cited by other publications.

Our main interest is whether an editor's university colleagues experience positive or negative productivity shocks around his appointment and/or departure. However, one empirical challenge is that in most cases, we observe only when an article is published, not when it was submitted. This requires us to estimate which editors handle which papers, based on publication dates. In our main tests, we use a lag of two years when matching editors with publications. ${ }^{6}$ This convention means that for an article published in 2005, we assume that the editor in residence during 2003 handled the review process. Because the typical editor is in place for about six years (Table 2, Row 3), what we assume here isn't as important as one might initially suppose, mostly because the editor one year ago and the editor two years ago is usually the same person. In any case, mismatching editors and authors is almost certainly idiosyncratic, and consequently, should bias downward any estimated effects. ${ }^{7}$

The data allow us to easily form two types of professional networks for editors - his current colleagues and past co-authors. A Colleague Connection is one in which an editor and author simultaneously work at the same university. For example, Richard Green from Carnegie Mellon edited the Journal of Finance from 2000 to 2003. We would therefore assign a Colleague Connection to any J ournal of Finance publication between 2002 and 2005, provided that one or more of its authors was also from Carnegie Mellon. As shown in Table 2, a little more than $7 \%$ of our articles have at least one Colleague Connection.

\footnotetext{
${ }^{6}$ See Ellison (2002) for a detailed review of the peer review process in economics journals. He documents a substantial slowdown, from, e.g., 6-12 months on average for general economics journals in the 1970s, to 2430 months in the 1990s. Over the last 20 years, the vast majority of journals had total review times between one and two years.

7 In Section 5 (Table 9), we repeat our analysis for a number of alternative cutoffs, and find minimal differences from the two-year cutoff we use in our main tests.
} 
A second way that editors and journal authors can be connected is through past coauthorships. Here, we use the WOS to infer authors with whom the editor of interest has published a paper in the past. Continuing with the example, J onathan Berk was a co-author of Richard Green before the latter began editing the J ournal of Finance. Consequently, we would assign a Co-author Connection to any of Jonathan Berk's J ournal of Finance publications between 2002 and 2005. These types of connections are, as shown in Table 2, about half as frequent, occurring about 3.2\% of the time. Aggregating both types, $8.8 \%$ of articles have a connection of some type.

An important caveat is there are many other types of relevant connections (e.g., an advisor- $\mathrm{PhD}$ relationship, graduate school classmates, etc.), that we do not consider. By ignoring these -- none of which we can observe from publication records -- we are almost certainly underestimating the size of any network effects.

The bottom part of Table 2 characterizes article quality using citation data. The main citation variable, Times Cited Count, is the measure of total citations gathered from Web of Science's five citation indices, and has been used in prior bibliometric studies (e.g. Wuchty, J ones and Uzzi, 2007). ${ }^{8}$ The average of Times Cited Count indicates that the typical article is cited slightly less than 33 times in any of the 224 economics journals listed in WOS.

However, as a foreshadow of our results in Section IV, the next two rows indicate that articles written by an editor's current colleagues or past co-authors, Connected Articles, are cited almost twice as frequently as Unconnected Articles (51.55 vs. 31.15). Of course, this is partly due to differences in author quality. Members of an editor's professional network, particularly for editors of prominent journals, are likely better trained, work at more prestigious institutions, or for other reasons are more productive. ${ }^{9}$ The next row gives a rough sense of this,

\footnotetext{
${ }^{8}$ See http://images.webofknowledge.com/WOKRS51B6/help/WOS/hp times cited count.html for a detailed description of the Times Cited Count variable.

${ }^{9}$ Our formal analysis of this issue will account for these differences, but for now, we simply note the univariate comparison.
} 
which shows that articles published only by co-authors at the top 50 schools, when ranked by number of publications, are cited more frequently, at about 44.5 average citations per article.

Moving to the bottom of the table, we see that Same-Journal Citations are relatively infrequent (mean 1.84), as are Self-Citations (mean 1.07). Finally, the average of Top 30 Journal Citations (9.11) indicates that only about 9.11/32.95, or $27 \%$, of total citations are attributable to cites in other top 30 journals.

\section{Editor-author connections and publishing success}

Our main research question is the following: upon assuming an editorship, do an editor's colleagues have more success publishing in his particular journal? To answer this question, we aggregate the 146 institutions which, at any point in the sample, have employed at least one editor of the 30 journals listed in Table 1. For each of these schools $i$, journals $j$ and years $t$, we count the number of publications, denoted Pubs $, \mathrm{j}, \mathrm{t}$. For example, Harvard-J ournal of Labor Economics-2006 would constitute a single observation, as would Duke-AER-1982.

Next we define a dummy variable, During $\mathrm{i}_{\mathrm{i}, \mathrm{j}}$, which equals one if school $\mathrm{i}$ had an editor at journal $\mathrm{j}$ during year $\mathrm{t}-2$, keeping in mind the two-year publication lag. In order to ascertain whether a school's publication rate at a specific journal is higher when an editor is there, we begin with the following linear model:

$$
\operatorname{Pubs}_{i, j, t}=\text { During }_{i, j, t}+\varepsilon_{i, j, t} .
$$

Residuals $\varepsilon_{i, j, t}$ are robust to heteroskedasticity, and are clustered by school. The results for this benchmark estimation for all 146 schools are presented in Column 1, Panel A, of Table 3. The positive coefficient of $1.421(\mathrm{p}<0.001)$ suggests that when a school hosts a journal, the editor's 
colleagues publish almost one-and-one-half more articles per year in that journal. To put this number in context, the mean value of Pubs is 0.35 , by almost any measure, an enormous effect.

However, it is immediately clear that this benchmark specification is grossly misspecified. One important reason is that more selective schools are more likely to employ editors, and likewise, are more likely to publish in top journals. Consequently, During $\mathrm{i}_{\mathrm{i}, \mathrm{t}, \mathrm{t}}$ at least in this regression, may mostly be capturing cross-school effects. The most direct solution is to include school fixed effects, but the data allow us to do considerably better. Given that our unit of observation is three dimensional $(i, j, t)$, we can admit pairwise fixed effects for each journalyear school-year, and school-journal unit. This procedure accounts not only for average crosssectional output differences between schools, but also for time-series changes in overall publication rates (school-year) and a school's persistent tendency to publish, or not publish, in a given journal (school-journal).

To gauge the incremental importance of each of these variables, we add them in sequence, beginning with Column 2, which takes the benchmark regression and adds only journal-year fixed effects. Although this nearly triples the Adjusted- $\mathrm{R}^{2}$, it leaves the coefficient of interest unchanged. This isn't particularly surprising, given that we are controlling for timeseries changes in journal size, which are essentially uncorrelated with During, but not for differences in author quality.

This is no longer the case in Column 3, where we now control not only for average differences in institutional quality, but also for each institution's average journal-specific match. This means that the coefficient on During $\mathrm{i}_{\mathrm{i}, \mathrm{t}, \mathrm{t}}$ is now estimated within journal-year units (e.g. comparing publication rates for UCLA in the AER during the years when it had an editor at AER (1981 - 1986) to the years when it did not (prior to 1981, or after 1986)). And as Column 3 shows, this makes a big difference, reducing the coefficient of interest from 1.43 to just 0.33 . However, keeping in mind the mean of the dependent variable, this nonetheless represents a marginal increase of nearly $100 \%$ relative to each department's baseline productivity. 
The final column adds school-year fixed effects, so that the specification now becomes:

$$
\operatorname{Pubs}_{i, j, t}=\text { During }_{i, j, t}+\sum_{j, t} J Y_{j, t}+\sum_{i, j} J S_{i, j}+\sum_{i, t} S Y_{i, t}+\varepsilon_{i, j, t}
$$

where $\sum_{j, t} J Y_{j, t}, \sum_{i, j} J S_{i, j}$ and $\sum_{i, t} S Y_{i, t}$ represent journal-year, journal-school and school-year fixed effects, respectively. This final model is akin to a triple-difference specification where we have netted out time-varying school quality, average school-journal matching effects, and the timevarying output for each journal. Continuing with the UCLA-AER example, During compares UCLA's 1983 publication output in the AER (where it had an editor) to UCLA's 1983 publication output in the QJE (where it did not), while also accounting for the fact that: 1) the AER might have published more papers than the QJ E in 1983 (it did), and, 2) that UCLA might persistently publish at a higher rate at the AER compared to QJ E (it has).

The results in Column 4 Panel A show virtually no change in the coefficient of interest. This is important because it suggests that whatever productivity improvements accrue to an editor's colleagues from hosting the journal, they are disproportionately captured by the editor's journal. This result is worth emphasizing. If the coefficient on During became insignificant when school-year fixed effects were introduced, it would be impossible to distinguish a casual story for editors from simultaneous improvements in overall institutional quality. That the coefficient remains significant, and moreover, that it remains virtually unchanged from Columns 3 to 4, suggests that upward shifts in a school's productivity around editorial appointments are not responsible for the effects we observe.

On the flip side, we might also have observed an increase in the coefficient on During when school-year effects were added. This would indicate a substitution effect (- e.g., Johns Hopkins faculty increasing their publication output in the American Economic Review at the expense of their output in the Quarterly J ournal of Economics during Robert Moffitt's tenure). While such a result might be interesting in its own right, the evidence instead points to editors 
discovering papers within their professional networks that otherwise wouldn't be published, at least not within the 30 journals in our set. For now, we postpone whether these discovered papers are "hidden gems," or whether editors engage in rent-seeking by lowering the quality standard for their friends and colleagues.

The next two Panels (B and C) of Table 3 repeat the same set of tests as in Panel A, but consider two subsets: the top three finance journals (J ournal of Finance, Review of Financial Studies, Journal of Financial Economics) and top five general-interest economics journals (American Economic Review, Quarterly J ournal of Economics, Journal of Political Economy, Review of Economic Studies, and Econometrica). These are interesting subsets because they reduce the substantial heterogeneity present in the full journal set. Thus, when we introduce school-year fixed effects into the regression (Column 4), the control set of background journals (e.g., the J ournal of Financial Economics in a regression of J ournal of Finance publications) becomes more comparable, and makes it easy to interpret any change in the coefficient.

Considering first the finance journals, we note similar and, from an absolute perspective, somewhat larger results. The magnitude on the During coefficient is about 1.2 without controls, settling to just over 0.6 with the full set of fixed effects. ${ }^{10}$ However, because the baseline publication rate among the finance journals is larger compared to the full set of 30 (averaging 1.3 articles per institution-journal-year), the marginal percentage increase is about $46 \%$.

Panel C considers only the top five general interest journals. Here, we see that accounting for schools, and in particular their matches with the top five journals, makes an enormous difference for the During variable. Comparing the second column (only journal-year fixed effects) and the third (which adds school-journal fixed effects), we see that school-journal

\footnotetext{
10 While the inclusion of school-journal fixed effects cuts the coefficient on During by nearly three-quarters in the sample of economics journals, the reduction is less pronounced (about one-half) in the finance sample. The most likely reason is that the variability of journal quality is much lower among the three "mainstream" finance journals listed. Consequently, while we might still expect large differences between schools (captured by the school-year effects), school-journal match effects for the finance journals (e.g., NYU Stern-Journal of Finance and NYU Stern-Review of Financial Studies) are almost certainly less informative than the the same matches in the broader sample.
} 
matches are responsible for the majority of the basic effect (about 88\%). However, with journalyear and school-journal fixed effects, the estimated coefficient on During of 0.29 publications is nevertheless significant at conventional levels. The final column, however, shows that adding school-year effects reduces the point estimate even further, and removes statistical significance (robust $\mathrm{t}=1.46)$.

The estimates presented in Table 3 explicitly account for time-variation in overall school productivity, time-variation in journal output, and time invariant school-journal matches. They do not, however, address school-journal matches that change over time. Particularly for the field journals, it is easy to see how the coefficient on During could become biased upward. Suppose a school wants to build up its econometrics group, and makes hiring and promotion decisions based on this desire. Around this time, suppose that one of its professors is selected to become an editor of J ournal of Econometrics or, for an even more direct channel, suppose that it hires an existing editor. If the department's output in this journal increased soon thereafter, it would be difficult to tell whether the editorial appointment itself or the department's emphasis on econometric research was the cause. ${ }^{11}$

Because our unit of observation is the journal-school-year, it is impossible to include dummy variables for each unique triple interaction. However, the structure of the data allows us to approximate this first-best scenario via a sequence of "false" editorial matches. The main idea is to isolate the specific years when During takes a value of one for a given journal and school, and bookend this time interval with placebo editorial matches that differ by a few years in either direction.

To illustrate, and continuing with the previous example, suppose that the J ournal of Econometrics editor served from 1999-2005. On the front end, we would apply false matches for five years preceding the actual appointment, i.e., assume that the editor began his tenure in

\footnotetext{
${ }^{11}$ Recall that such an argument cannot be made for general productivity, or output averaged across all journals. The inclusion of school-year fixed effects means that any remaining alternative must be time varying, and within a given journal or set of closely related journals.
} 
1998, 1997, 1996, 1995, or 1994. Take 1996 as an example of a false match. Recalling that we are imposing a two-year delay, we would be looking for spikes in the department's 1998 output in the J ournal of Econometrics, which, because it precedes the editor's actual appointment, cannot be causally related to his influence. However, assuming that the department's emphasis on econometrics is likely to manifest over (at least) a couple of years, this placebo test allows us to quantify what portion, if any, of the During effect is due to time-variation in a school's emphasis on certain fields. The same logic applies to the back end, where we could apply false matches for the years 2007, 2008, and so on.

Panel A Table 4 shows the results of these falsification tests, where the variables JustBefore and J ustAfter represent five-year placebo editorial matches. In the first column, we conduct the estimation with ordinary least squares, as we did in Table 3. Here, the relevant comparisons are between the true During variable and either of the false matches. The coefficient on During is nearly identical to Column 1 of Table 3, at slightly under 1.5 publications per journal-year. More importantly, it is almost double the size of either the J ustBefore (0.82) or J ustAfter (.80) coefficients. Both differences are highly significant ( $\mathrm{p}<0.001)$. Recalling that the false matches are formed at the journal-school-year triple, differing only by a few years from actual editorial matches, these results suggest that there is something special about the precise years when an editor serves.

The J ustBefore and J ustAfter placebo matches aggregate the five years immediately preceding, and immediately following, respectively, each editor's tenure. We do this for parsimony, but one could just as easily estimate separate false matches, one for the first year before the start of an editor's tenure, a second for two years before, etc. Figure 1 shows these estimates in graphical form, rather than what would be a long and somewhat cluttered table. 
The middle region, labeled "During Connected Editorship," shows the average value for the estimated coefficient on During, about 1.4, as in Table 4.12

On the front side, we see that five, four, three, and two years before his appointment, the editor's school publishes about 0.8 papers in the journal of interest, then rises to 1.0 in the year directly before he assumes his post. Given that we are assuming a two-year lag, some of this could be measurement error (e.g., an editor who takes over J anuary 2001 and publishes his first paper in October 2002), which we would incorrectly call a false match. In any case, this effect is relatively small. The main takeaway from Figure 1 is that the effect of an editor's appointment is fairly abrupt, both at the front and back of his tenure. While one could still possibly tell a story about time-varying matches between schools and journals, the discrete nature of the productivity changes would appear to strain the plausibility of such alternatives.

Apart from providing arguably tighter identification, the false editorial match procedure has the added advantage of not requiring the estimation of thousands of fixed effects. This reduction in computational demand allows us to augment the OLS shown in Column 1 with Poisson and Negative Binomial models. Because our dependent variable is both discrete and restricted to non-negative values, econometric techniques that explicitly account for these features are desirable. ${ }^{13}$ However, Columns 2 and 3 of Table 4 show only modest differences. While the estimates on J ustBefore and J ustBefore are about .3 larger compared to OLS, so too is the estimated coefficient on During, resulting in about the same marginal increases. Also, as in Column 1, both relevant nulls (i.e., that the coefficients on J ustBefore and During are equal, and that the coefficients on J ustAfter and During are equal) are rejected at better than the $1 \%$ level for both models.

Following Table 3, we repeat this exercise for the finance and general economics journals separately. In these much smaller samples, the burden on the data becomes apparent,

\footnotetext{
12 The During region in Figure 1 is the average effect over all years during an editor's appointment. We show the coefficient over five years purely as a visual aid, meant to roughly match the typical editor's tenure.

${ }^{13}$ See Long (1997) for a thorough description of Poisson, Negative Binomial and other models of count data.
} 
particularly with regard to statistical significance. Nonetheless, it is useful to see the point estimates - all of which go in the same direction as in the full sample - even when the differences are not always statistically significant. In particular, the estimated coefficients on false matches on the back of editorial tenures (JustAfter), while consistently lower than the estimates on the authentic matches (During), are much closer to one another, compared to the full sample.

On the other hand, the false editorial match procedure yields particularly strong results for the general economics journals, as shown in Panel C of Table 4. Under the OLS procedure, shown in Column 1, actual editorial matches increase output by over a factor of two relative to placebo matches. The magnitudes are smaller with the Poisson or Negative Binomial models, but the ratios of the estimated coefficients are similar. In all three columns, the estimated coefficients on the genuine matches are statistically higher than estimates on either side, i.e., on J ustBefore or J ustAfter.

\section{Mechanism}

The remainder of the paper takes as given the results in Tables 3 and 4 , and attempts to better understand the underlying reason. There are three main possibilities. The first is rentseeking: if editors obtain private benefits by bestowing favors upon members of their network, and if professional sanction or other implicit incentives are insufficient deterrents, we might expect editors to publish more, but lower quality, papers written by colleagues or past coauthors.

A second, and decidedly less cynical possibility is a simple productivity story. For a variety of reasons, hosting a journal may temporarily boost the productivity of a faculty member. Perhaps the most direct is that being awarded an editorship increases the prestige or visibility of the editor's institution. This might lead, for example, to more engagements with high quality 
seminar speakers or other interactions, perhaps fostering co-authorships. Likewise, perhaps increased refereeing work, although potentially crowding out research, might force an editor's colleagues or co-authors to think harder about problems, or observe real-time publication trends or tastes, either of which could increase the quality of their own papers.

Finally, perhaps an editor's colleagues are neither more nor less productive, but nevertheless benefit from the editor seeing their paper through a "clearer lens." While it may not be immediately obvious that this can increase the number of published papers for members of an editor's network (while it is easy to see how average quality would increase), we present a stylized model that shows how it is possible. The intuition is simple. Think about a paper that has the potential to revolutionize a field, but doesn't fit neatly within the existing literature. Gans and Shepherd (1994) regale the experiences of a number of Nobel laureate economists, whose ultimately influential papers faced early resistance with journals. In such cases, one can easily imagine how a well-informed editor - perhaps a co-author or colleague of an author would help identify such diamonds in the rough.

Here, we attempt to distinguish between these possibilities. In subsection IV.a, we explore the citation counts of papers connected to an editor - those written by his institutional colleagues and past co-authors - in an attempt to detect inefficient favoritism. Subsection IV.b discusses in more detail the productivity story, the idea that hosting a journal confers temporary productivity advantages to the faculty of the editor's institution. Finally, the last subsection (IV.c) presents a simple model based on the idea that editors familiar with a paper's authors may be better able to assess its quality. As we will see, this simple model reconciles nearly all of the results in the paper, and generates a few new predictions that appear to have empirical support. 


\section{a. Favoritism}

In Gans and Shepherd's (1994) article mentioned above, Richard Posner's quote stands out: "I have had papers turned down, all right, but very few economics papers. Most of my economics papers have been published by close friends....and in many of these cases there weren't even formal submissions (p. 1972)." The obvious question is whether such instances are good or bad for the profession, i.e., whether an editor friendly to Posner forgoes higher quality papers for the sake of a personal relationship. Assuming that cite counts are a valid, objective measure of article quality - an assumption we will test explicitly - comparing citation counts for papers connected to an editor to papers lacking a connection helps us identify editorial favoritism.

For each article in the 30 journals listed in Table 1, we collected the number of citations the article has received from Web of Science (Times Cited Count). We defined a variable LogCites $_{k, j, t}$ which is the natural logarithm of Times Cited Count for article k in journal $\mathrm{j}$ in year t. Note that Times Cited Count includes citations in the entire Web of Science, not just the 30 for which we have editorial information. Later, we vary this definition.

As with the publication rate regressions, we begin with the simplest model, estimating:

$$
\text { LogCites }_{k, j, t}=\text { Connection }_{k, j, t}+\varepsilon_{k, j, t},
$$

where Connection $_{\mathrm{k}, \mathrm{j}, \mathrm{t}}$ represents either an editor-author colleague relationship, an editor-coauthor relationship, or the union of the two. The results are presented in Columns 1- 3, Panel A of Table 5. The positive coefficients on the different connection variables vary between 0.350 and 0.425 ( $\mathrm{p}<0.001)$, suggesting that on average, connected articles receive on the order 35 $43 \%$ more citations. 
However, the same types of selection concerns that apply to the publication rate regressions (Tables 3 and 4) apply here. Specifically, we already know that connected articles, having been written by academics affiliated with an editor, are not of random quality. Faculty from prestigious schools are more likely to be selected as editors, as are academics with impressive publication records (perhaps due in part to well chosen co-authors). Consequently, it is important to account for author quality, which we do in the next three columns.

Perhaps the most straightforward way to control for author quality is to measure his (or, in the case of a group, their) recent performance, as measured by citation counts. With the variable Times Cited Count: Last 5 Years, we perform the following exercise: for every paper in our data set published in year $\mathrm{t}$, we tabulate the citation counts for each author over the trailing five years, and then take the maximum. To give an example, suppose that three co-authors A, B, and C, published a paper in 1998. Furthermore, suppose that co-author A's papers from 19931997 were cited 24 times, co-author B's papers were cited 15 times, and that co-author C's papers were cited 43 times. In this case, the Times Cited Count: Last 5 Years would take a value of 43 , corresponding to the recent cite counts of co-author $\mathrm{C}$. This metric pays special attention to the tails of the citation distribution, which, as we already know, is highly skewed (Table 2). However, alternatives such as summing the cite counts or averaging them makes little difference.

The fourth column shows, unsurprisingly, that accounting for recent citations is very important. Co-author groups with highly cited papers in the recent past continue to have their papers cited, described as the "Matthew effect" by Merton (1968). It also includes as a control the Number of Authors for each paper; the negative coefficient is not particularly meaningful in this context, given that it is highly correlated with Times Cited Count: Last 5 Years variable.

The estimate on Any-Connected Article remains economically and statistically significant at $0.250(\mathrm{p}<0.001)$, indicating that relative to the recent performance of a co-author 
team, connected articles are of higher quality. Note that this column also controls for journalyear fixed effects, i.e., with separate dummy variables for AER-2004, AER-2005, etc.

While Times Cited Count: Last 5 Years controls for quality through lags of the dependent variable, it cannot account for young authors who, prior to the year of consideration, have scant publication records. To account for cross-sectional differences in author quality using a non-parametric framework, the last two columns include dummy variables for schools (Column 6) and individual authors (7). The number of authors well exceeds the number of articles in our data set, so we include 500 fixed effects for the most prolific authors. Because we are mostly concerned about the right tail of the distribution, the set of 500 fixed effects for top authors are probably sufficient to capture the early successes of eventual stars (e.g., Kyle (1985)).

While the inclusion of these controls substantially cuts the point estimates - suggesting the importance of early publications in our analysis - connected papers still receive higher citation counts. In particular, note the demands of the final specification, which effectively takes the top 500 authors in economics over the last 50 years, and parses line items within each author's curriculum vitae as being connected to the publishing editor or not. The point estimate indicates that citations increase by about $9 \%$ relative to other articles published in that journal, during that year.

In the finance and general economics subset, shown in Panels B and C, respectively, we see similar findings, although as we saw earlier, the substantial drop in statistical power takes a toll. Focusing only on the last column with author fixed effects, we see an almost $20 \%$ increase in citation counts for papers written by an editor's university colleagues or previous co-authors, although this result is weaker than in the full sample, with a p-value equal to $8 \%$. Among the set of general economics journals, probably the most one could conclude is that connected articles are no worse - although perhaps no better either - than unconnected articles. Using only lagged citation counts to capture author heterogeneity (Column 4), we estimate a citation 
premium of over 30\%. However, either school (Column 5) or author (Column 6) fixed effects virtually wipes out this coefficient; while both have positive estimates, they are very small economically and statistically.

In summary, the analysis of citation counts gives no indication whatsoever that editors engage in inefficient favoritism by lowering the quality standard for friends or colleagues. However, this is true only insofar as editors cannot use their power to influence a connected article's citations. For example, an editor may place connected articles at the front of an issue (Oswald, 2008), or he may ask future papers to cite connected articles. In either case, we are left with the possibility that our measure of paper quality is itself contaminated by editorial favoritism.

We begin with an examination of article placement, i.e., whether an article is placed first, second, third, etc., in a given issue. Because editors control placement, then provided that citation counts are causally related to placement, this might constitute a tool by which quality measures can be manipulated. There are channels through which this might occur. One is simply limited attention, i.e., that authors are less aware of articles published near the back of an issue - an effect perhaps limited to pre-internet years when physical copies of journals were how articles reached their target audiences. A second possibility is that editors have private information about the quality of a given article (e.g., from referee correspondence), and communicate this information via placement. In either case, the editor's choice has a causal impact on cite counts.

On the other hand, the placement of articles might simply reflect editorial convention, whereby higher quality articles are placed earlier in issues. Under this story, there is no causal role for an article's placement, so that randomly shuffling articles within an issue would have no impact on its eventual citation count.

For the moment, we leave this ambiguity unresolved, and simply quantify whether, and if so, by how much, article placement matters for cite counts. We again consider the LogCites 
variable (defined above) as well as the dummy variables First Article, Second Article, and Third Article. As their names suggest, First Article equals one if the article is the first in the issue, Second Article equals one if the article is the second in the issue, and so on. Columns 1-3 of Table 6, Panel A show the results. All else equal, lead articles are cited about 50\% more than other articles published in that journal during that year. Articles in the second slot fall to about half the magnitude (26\%), and articles placed third are cited about 17\% more than the typical article. In summary, we see that article placement is strongly associated with citation counts, but for the reasons described above, the direction of causation is unclear.

In Panel B, Columns 1-4, we take the relation between article placement and citations (Panel A) as given (and again punt on causation for the moment), and simply ask whether connected articles enjoy better placement. To do so, we estimate the following equation:

$$
\text { LeadArticle }_{k, j, t}=\text { Connection }_{k, j, t}+\text { PastCites }_{k, j, t}+\text { NumAuthor } \varsigma_{k, j, t}+\sum_{j, t} J Y_{j, t}+\varepsilon_{k, j, t},
$$

where the dependent variable is discrete, taking a value of one if an article is placed in the lead position, and zero otherwise. Regardless of the type - i.e., either a Colleague Connection or Coauthor Connection - connected articles are 5-7\% more likely to be placed in the lead position. This result is virtually unaffected by including controls for past citation counts (Times Cited Count: Last 5 Years), Number of Authors, or journal-year fixed effects.

This result, however intriguing, is not a smoking gun. The reason, as mentioned above, is that editors may simply follow a convention of placing higher quality articles earlier in issues. For this reason, we examine a second type of discretionary placement, and importantly, one that does not suffer such an ambiguous interpretation. The idea is as follows: while placement within an issue likely reflects an editor's assessment of article quality, placement across issues within a year does not. To be concrete, suppose that we are thinking about two generic months in which the Quarterly J ournal of Economics regularly publishes: May and August. Although it 
is plausible that the respective lead articles in either month are of higher than average quality, it would be surprising for lead articles in May to systematically differ from lead articles in August. Similar logic applies to articles placed in other slots.

Given this logic, the fourth column shows the results of the following exercise. The thought experiment is to compare the citation counts for two non-lead articles published in the same journal-year, but where only one of them follows a "star" lead article, i.e., is in the same issue. For example, imagine articles like White (1980) or Jensen and Meckling (1976), incredibly influential papers by any measure. We are interested in whether these star articles confer "citation spillovers" to other articles within the same particular issue. Presumably, readers seeking out star articles may have stumbled upon articles in the same issue, and consequently, contributed to increased citation counts.

And indeed, this is exactly what appears to happen. When we define Star Articles as the highest cited lead articles in a particular journal year (e.g., the highest cited of Quarter J ournal of Economics's lead articles in 1997), we observe spillovers to other articles in the same issue of about $8 \%(\mathrm{p}<0.001) .{ }^{14}$ Comparing this estimate (Column 4 of Panel A) to previous columns, this effect is similar to the citation difference between a second and thind placed article.

To complete the argument, all we need is for editors to have some idea of which articles are likely to be stars. It seems difficult to believe otherwise, given that editors have likely observed a number of quality signals by the time placement decisions are made, and that we are restricting attention to lead articles. Provided that they do, then the question is whether they "stack" connected papers in the same issues as, say, White (1980) in order to reap the 8\% incidental citation spillover. The final column of Panel B of Table 6, where we include the full family of controls, suggests not. Here, we see that connected articles are no more (or less) likely to be placed in the same issue as a Star Article. This result, which does not suffer the same

\footnotetext{
${ }^{14}$ We focus on lead articles because we are interested in situations where the editor has information about an article's eventual success. Articles whose high citation counts surprised even the editor can clearly not be used in the manner hypothesized.
} 
ambiguity as the results in Panel B, Columns 1-4 - or if it does, certainly suffers less - suggests that the higher lead probabilities we see for connected articles reflect their inherent quality, not editors handing out placement mulligans to their friends.

A second, and perhaps more direct, way editors might influence citations counts is by encouraging other papers to cite connected papers. This is a specific case of the more general criticism that citations should perhaps be weighted differently. For example, one might view citations in the connected editor's journal as less objective (for the reason described above), similar to the arguments levied against self-citations as a measure of quality. In Table 7, we conduct robustness exercises dedicated to these and similar concerns.

The first three rows investigate the possibility that the extra citation counts for connected articles stem disproportionately from articles within the same journal. Although this would not necessarily indicate inflated cite counts from editorial pressure, excluding them means that our effects are identified purely from articles outside the editor's sphere of influence. Although the magnitudes are slightly reduced, we observe very similar magnitudes for the full sample. Through similar logic, the final column excludes self-citations which, as Table 2 shows, amount to a trivial percentage of overall cites. Perhaps unsurprisingly, excluding them makes almost no difference.

\section{b. Productivity}

If editors are publishing more of their colleagues' papers, and if these papers are of higher average quality, it is possible that journals confer genuine productivity advantages to an editor's colleagues and perhaps his co-authors as well. We have already mentioned a number of ways this could happen, including more visibility for the department, refereeing opportunities that stimulate research ideas, better exposure to seminar speakers, and numerous other 
possibilities. While all of these mechanisms have a certain plausibility, and must be true to some extent, two pieces of evidence suggest that they are not the main story.

The first, to which we have already alluded in the discussion of Table 3, is that when an editor is appointed, we see higher output only in his journal, and not in other similar journals. This was evident when we added school-year fixed effects to the models that only included school-journal fixed and journal-year fixed effects (Columns 4 in Panels A, B, and C in Table 3), which implicitly control for each school's average productivity across all other journals except the editor's own journal. In Table 8, we show this even more explicitly. Here, we are particularly interested in comparing very similar journals, and thus, restrict attention to the three top finance journals (J ournal of Finance, Review of Financial Studies, and J ournal of Financial Economics).

Now, the thought experiment is as follows. When Campbell Harvey assumed the editorship of the J ournal of Finance, we consider as the dependent variable Duke's output in either the J ournal of Financial Economics or the Review of Financial Studies. Following Table 4, we also include false editorial matches for five years on either side of an editor's tenure. The results in Table 8 are clear. Whether estimated with OLS (Column 1), Poisson (Column 2), or Negative Binomial models (Column 3), their J ustBefore, During, and J ustAfter have virtually identical magnitudes. This means that for the decade (or so) surrounding an editor's appointment, the department's output is higher than during other times; however, in stark contrast to Table 4, there is nothing special about the specific years (when During takes a value of one) an editor serves.

The second piece of evidence challenging the productivity story is the steepness of the ramp up we observe when an editor is appointed. As our analysis of false editorships makes clear (shown graphically in Figure 1), the exact years an editor is in residence are crucial - a year or two in either direction shows steep declines. It is difficult to imagine a time-varying, schooljournal productivity effect persistently correlated with editorial arrivals and departures. The 
only plausible way this could occur is if schools hire active or soon-to-be editors, which represents a discrete shock to a department's productivity. Yet, inspection of the data reveals that these occur very infrequently, and even so, if we remove an editor's own publications from the analysis, virtually nothing changes.

\section{c. Information}

The final mechanism we consider is that editors are simply more informed about papers written by members of their professional network. While it is easy to imagine that informed editors might select better papers, how this implies more publications isn't immediately obvious. Here, we present a simple framework that simultaneously delivers both predictions.

Suppose that an academic can write two types of papers: boring (B) and exciting $(\mathrm{E}){ }^{15} \mathrm{~B}$ papers fit easily within the context of a given literature, and consequently, have merits that are easy to evaluate. To capture this idea, assume that editors observe the quality of a B paper, $\mathrm{q}_{\mathrm{B}}$ without error. Furthermore, assume that all boring papers have the same quality, i.e., $\mathrm{q}_{\mathrm{B}, \mathrm{i}}=\mathrm{q}_{\mathrm{B}, \mathrm{j}}$ $=q_{B}$, for all papers $i, j$.

On the other hand, there are two reasons why E papers are more problematic for editors. First, they have variable quality. A given E paper, i, can be either path breaking, in which case its quality is $\mathrm{Q}>\mathrm{q}_{\mathrm{B}}$. Alternatively, an $\mathrm{E}$ paper can be a "dud," which is normalized to have zero quality. Denoting the probability of an E paper being path breaking as $\mathrm{p}$, the unconditional, expected quality of an E paper is Qp.

Second, although editors can easily tell E and B papers apart, distinguishing between good E papers (quality of Q) and dud E papers (quality of zero) is hard. To capture this idea,

\footnotetext{
${ }^{15}$ One could easily view this distinction in the context of Ellison's (2002) $q-r$ theory of publishing, in which $q$ papers represent fundamentally new ideas, and $r$ papers represent "other" dimensions of quality like robustness. In our model, there is only one dimension of quality, but two types of papers with different unconditional distributions of this quality measure.
} 
suppose that upon receiving $E$ paper $\mathrm{i}$, an editor receives a binary signal (high or low), $\mathrm{S}_{\mathrm{E}, \mathrm{i}}$, that is positively correlated with paper quality as follows:

$$
S_{E, i} \mid\left(q_{E, i}=Q\right)=\left\{\begin{array}{c}
\text { high } w / \text { prob. } x \\
\text { low } w / \text { prob. } 1-x
\end{array}, x \geq \frac{1}{2} .\right.
$$

A symmetric case applies, i.e., if $\mathrm{q}_{\mathrm{E}}=0$, a low signal will be received with probability $\mathrm{x}$, and a high signal with probability 1-x. The higher the value for $\mathrm{x}$, the more informative is the editor's signal of an E paper's quality. There are two relevant regions for x:

Case 1. $x<x^{*}=\frac{q_{B}(1-p)}{p\left(Q-q_{B}\right)+q_{B}(1-p)}$. If the editor's signal about E paper quality is sufficiently low, then even in the event that he receives a high signal, the posterior expectation of paper quality, $\frac{p x}{p x+(1-p)(1-x)} Q$, is lower than the quality of a B paper, $\mathrm{q}_{\mathrm{B}}$.

Case 2. $x \geq x^{*}=\frac{q_{B}(1-p)}{p\left(Q-q_{B}\right)+q_{B}(1-p)}$. Here, the editor's signal is informative enough so that if he receives a high signal, his posterior quality assessment (at least) exceeds the quality of a B paper.

Assume now that editors make decisions taking into account only a paper's expected quality, given any signals received. Suppose further that an editor publishes $\mathrm{T}$ total papers per year, and that far more than this number of both E and B papers are submitted for publication. Finally, suppose that the members of an editor's network submit N “exciting” papers, where, both because it is probably realistic and to keep the expressions simple, we assume that $\mathrm{N}<\mathrm{T}$. 
For the $\mathrm{N}$ number of connected exciting papers, Case 2 applies, so that the editor can distinguish duds from home runs. For the remainder of exciting papers, Case 1 applies.

Under these assumptions, it is easy to see how the model plays out, both in a static and dynamic sense. In any given year, an editor receives $\mathrm{N}$ exciting papers from within his network, of which we will fraction $q$ in expectation. No other $E$ type papers are published, because even if the editor gets a positive signal, the information isn't valuable enough to offset the considerable downside. As editors rotate, the set of papers for which Case 1 and 2 applies also changes, which explains the increase in publication output for an editor's colleagues upon his appointment (Tables 3 and 4). Note also that the papers themselves do not change when editors rotate; only which papers receive informative versus relatively uninformative signals does.

It is equally easy to see that editorial connections improve the journal's overall quality. With $\mathrm{T}$ papers published, the average quality is $\frac{T-N[p x+(1-p)(1-x)]}{T} q_{B}+\frac{N p x}{T} Q>q_{B}$. The second term represents the impact (Q) of the high quality E papers that make it through the review process, and the first term accounts for the fraction of B papers of lower average quality $\left(\mathrm{q}_{\mathrm{B}}\right)$. Note also that because editors still make some mistakes, there are $N(1-p)(1-x)$ papers of quality zero that are published. Nonetheless, the model predicts that although E papers are of lower average quality, the special ability of informed editors means that some of them - and only the good type - will be published. This raises average quality, and reconciles the citation evidence in Tables 5 and 6.

Finally, note that the model makes a final prediction about the variance in citation quality, which we have so far ignored. Trivially, unconnected articles are all of quality $\mathrm{q}_{\mathrm{B}}$, for a variance of zero. In contrast, published connected articles, even though of higher average quality, also have higher conditional variance (assuming the editor's signal is not perfect). Specifically, the variance of quality for connected published articles is $\frac{Q^{2} p x(1-x)(1-p)}{[p x+(1-x)(1-p)]^{2}}>0$. 
As $x \rightarrow 1$, so that the editor's assessment of $E$ papers gets better, the variance in citation quality among published papers approaches zero. In any case, although not the main focus of our analysis, we simply note that from Table 2 , the variance of connected articles is substantially higher (165 vs. 98), which is also consistent with the model's predictions.

In summary, while nepotism, enhanced productivity, and informed editors can also explain why an editor's colleagues might experience shocks to their publication rates, the first two fall short in important ways. Editorial rent-seeking is rejected directly by the fact that citation counts are higher, not lower, for papers connected to the editor. Enhanced productivity, while possible, implies unrealistic time-series patterns in each school's journal-specific productivity, specifically ones that spike steeply upon an editor being appointed, and drop off after he retires. In contrast, a relatively simple model of informed editors reconciles all the patterns we document.

\section{Robustness}

Throughout the analysis, we are forced to make several subjective calls. In this short final section, we present our main results under different assumptions for two of our most important variables: 1) how an editor is matched to published articles, and, 2) what constitutes a valid citation.

All previous tables assume a two-year lag between publication and submission, an assumption required because in the vast majority of cases, only the active editor is specified in a journal's front matter. This is bound to result in mismatches, both on the front and back end of an editor's tenure. Some evidence consistent with such mismatching we've already seen in Figure 1, which shows a marked uptick in the year before an editor's tenure, from 0.8 articles/year in year t-2 to 1.0 articles/year in year $\mathrm{t}-1$. Any articles taking less than two years to 
show up in print will be captured by the $\mathrm{t}-1$ false matches, and will bias downward the coefficients of interest.

Because we don't observe when papers are submitted, there is no obvious solution to this problem. So, in Panel A of Table 9, we present our main results under a number of alternative assumptions. In Column 1, we assume a one-year publication lag, almost certainly too short for the typical article. Column 2 presents the results assuming a three-year publication lag, which probably errs in the opposite direction for all but perhaps a few theory journals late in the sample. The final column applies a publication lag that increases with time, using Ellison's (2002) Table 1, which provides some empirical guidance. ${ }^{16}$ However, as the table indicates, our results are not particularly sensitive to this assumption. In every case, the estimated OLS coefficients in Table 9 are virtually indistinguishable from Column 1 of Table 4. Mainly, this is because the typical editor serves for several years (Table 2), and what we assume about publication lags only matters at the endpoints, which, as Figure 1 illustrates, represents only a small percentage of the total editorial matches.

The bottom Panel (B) of Table 9 provides additional robustness to how we measure citation counts. First, to remove the possibility that citations are disproportionately picking up activity from less prestigious journals (recalling that there are 224 economics journals listed in WOS), we include only cites from articles published in the top 30 economics journals. Except for this redefined dependent variable, the specification otherwise matches the one with results shown in Table 5. That is, PastCites and NumAuthors are included in each specification, the first regression for each dependent variable includes journal-year fixed effects, the second journal-year and school fixed effects, and the third journal-year and author fixed effects. Comparing these results to the full sample, we observe similar, but even stronger effects. The

\footnotetext{
16 It is important to note that Ellison (2002) presents the total time to acceptance, not to publication, which is ultimately what we observe.
} 
fact that the best journals are citing connected articles with higher frequency gives credence to the claim that they are, in fact, of higher objective quality.

The final three columns remove the influence of very highly cited articles by winsorizing at the $1 \%$ level. While it is not a priori clear why one would want to reduce their impact in the estimation - indeed, one could make the opposite claim - the results survive, with magnitudes similar to those observed in Table 5.

\section{Conclusion}

The long-run quality of academic research (citations) is ultimately judged as most other goods - by a largely anonymous market. However, short-run quality decisions (journal acceptances) are made by a small number of individuals, and thus admits the possibility for conflicts of interest to bias decision making. Because these two are linked - i.e., whether and where an article is published may impact how influential it can become - the credibility of the editorial process is of paramount importance. Also of consequences are career and tenure outcomes, many of which are linked directly to publications (perhaps less so to citation counts).

This paper examines whether editors of academic journals admit more of their colleagues' papers to their own journals, and if so, whether these papers deserved to be accepted. Examining over 50,000 articles from 30 top economics and finance journals since 1955, we provide strong affirmative answers to both questions. Although members of an editor's network publish at higher frequencies at the editor's journal, the citation counts for such papers are at least $5 \%$ higher, and up to $25 \%$ higher. Our specifications are stringent, accounting for timevarying school quality, time-varying journal quality, school-journal match effects, and even author fixed effects.

Whether these results are remarkable or not largely depends on one's view of an editor's incentives. On the one hand, editorial positions are almost always pro bono, implying little if 
any direct pecuinary incentives. On the other hand, the perception of corruption is likely quite costly to editors, let alone intrinsic motivation, the combination of which appears to be capable of reducing agency costs. 


\section{References}

Banerjee, Abhijit and Kaivan D. Munshi, 2004, How Efficiently is Capital Allocated? Evidence from the Knitted Garment Industry in Tirupur, Review of Economic Studies, Vol. 71, No. 1, 19-42.

Costa, Dora L. and Matthew E. Kahn, 2007, Surviving Andersonville: The Benefits of Social Networks in POW Camps, American Economic Review, Vol. 97, No. 4, 1467-1487.

Ellison, Glenn D., 2002, The Slowdown of the Economics Publishing Process, Journal of Political Economy, Vol. 110, No. 5, 947-993.

Ellison, Glenn D., 2002, Evolving Standards for Academic Publishing: A q-r Theory, J ournal of Political Economy, Vol. 110, No. 5, 994-1034.

Fisman, Raymond, Daniel Paravasini, and Vikrant Vig, 2011, Social Proximity and Loan Outcomes: Evidence from an Indian Bank, Working Paper.

Gans, J oshua and George B. Shepherd, 1994, How Are the Mighty Fallen: Rejected Classic Articles by Leading Economists, The J ournal of Economic Perspectives, Vol. 8, No. 1, 165179 .

Granovetter, Mark, 1974, Getting a J ob: A Study of Contacts and Careers, Harvard University Press (Cambridge, MA).

J ackson, C. Kirabo and Henry S. Schneider, 2011, Do Social Connections Reduce Moral Hazard? Evidence from the New York City Taxi Industry, American Economic J ournal: Applied Economics, Vol. 3, No. 3, 244-267.

J ensen, Michael C., and William H. Meckling, 1976, Theory of the Firm: Managerial Behavior, Agency Costs, and Ownership Structure, Journal of Financial Economics, Vol. 3, No. 4, 305-360.

Kyle, Albert S., 1985, Continuous Auctions and Insider Trading. Econometrica, Vol. 53, No. 6, 1315-1335. 
Laband, David N. and Michael J. Piette, 1994, Favoritism versus Search for Good Papers: Empirical Evidence Regarding the Behavior of Journal Editors, Journal of Political Economy, Vol. 102, No, 1, 194-203.

Long, J. Scott. 1997, Regression Models for Categorical and Limited Dependent Variables. London: Sage Publications.

Medoff, Marshall H., 2006, The Efficiency of Self-Citations in Economics, Scientometrics, Vol. 69, No. 1, 69-84.

Merton, Robert K., 1968, The Matthew Effect in Science, Science, Vol. 159, No. 3810, 56-63.

Oswald, Andrew J ., 2008, Can We Test for Bias in Scientific Peer-Review?, Working Paper.

White, Halbert, 1980, A Heteroskedasticity-Consistent Covariance Matrix Estimator and a Direct Test for Heteroskedasticity, Econometrica, Vol. 48, No. 4, 817-838.

Wuchty, Stefan, Benjamin F. J ones, and Brian Uzzi, 2007, The Increasing Dominance of Teams in Production of Knowledge, Science, Vol. 316, No. 5827, 1036-1039. 


\section{Figure 1: Marginal publication rates before, during and after connected editor's tenure}

The figure plots coefficients from the specification in Table 4, Panel A, Column 1 except separate coefficients are estimated for dummy variables 1 , 2, 3, 4 and 5 years before an editorship (J ust Before) and 1, 2, 3, 4 and 5 years after an editorship (J ust After). The coefficients represent the marginal change in publication frequency for school i in journal $\mathrm{j}$ in the five years before that school's editor arrives at journal $\mathrm{j}$, during his tenure, and in the five years after he leaves. Economics J ournals are all 30 journals from Table 1.

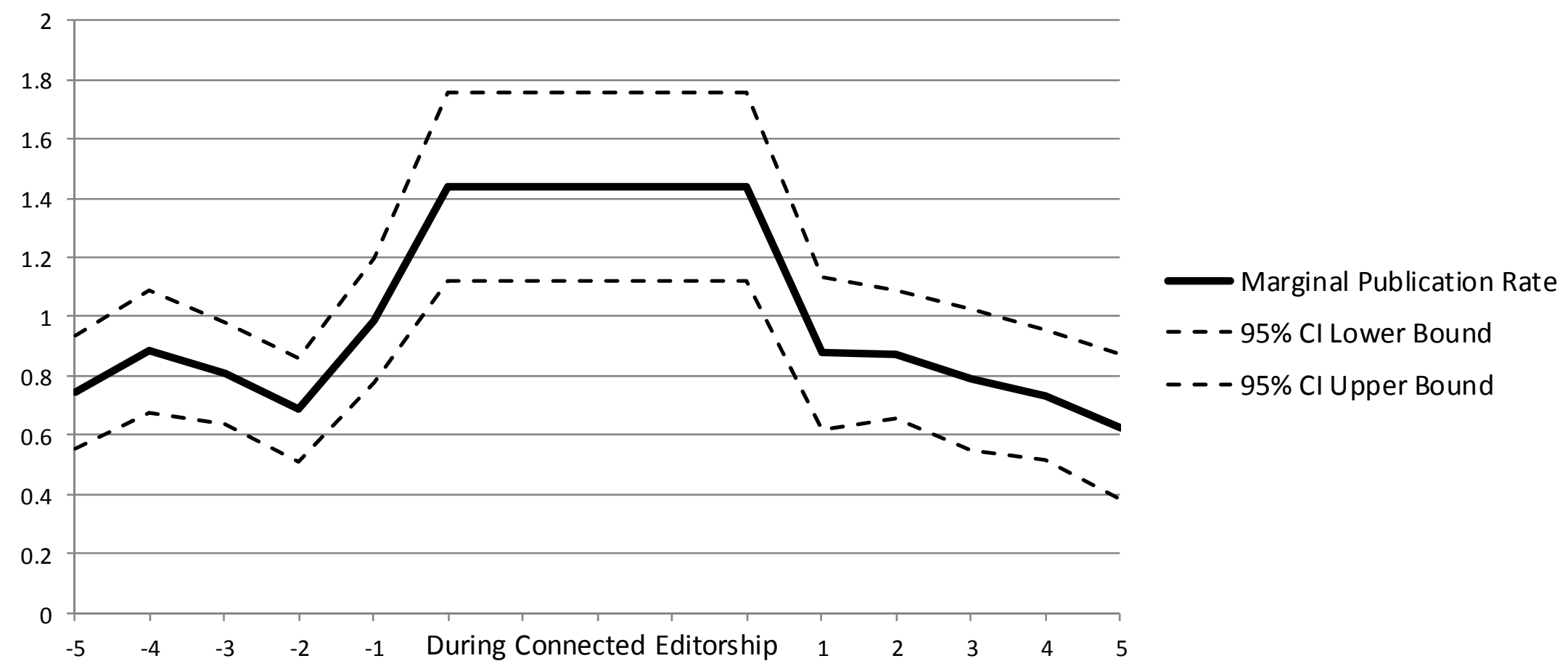




\section{Table 1: J ournal list}

The table lists 30 major economics journals for which we have detailed editorial histories. House J ournal is "Yes" if every year of the editorial history contains at least one editor from the same university (e.g. Harvard and the Quarterly J ournal of Economics). First Year in Sample is the first year the journal's publications have full records in the Web of Science database.

\begin{tabular}{|c|c|c|c|}
\hline & Journal & $\begin{array}{l}\text { House } \\
\text { Journal? }\end{array}$ & $\begin{array}{l}\text { First Year } \\
\text { in Sample }\end{array}$ \\
\hline 1 & ECONOMETRICA & No & 1955 \\
\hline 2 & J OURNAL OF ECONOMIC LITERATURE & No & 1969 \\
\hline 3 & J OURNAL OF POLITICAL ECONOMY & Yes & 1956 \\
\hline 4 & JOURNAL OF FINANCIAL ECONOMICS & Yes & 1976 \\
\hline 5 & QUARTERLYJ OURNAL OF ECONOMICS & Yes & 1956 \\
\hline 6 & AMERICAN ECONOMIC REVIEW & No & 1956 \\
\hline 7 & J OURNAL OF ECONOMIC PERSPECTIVES & No & 1988 \\
\hline 8 & J OURNAL OF FINANCE & No & 1956 \\
\hline 9 & J OURNAL OF LAW \& ECONOMICS & Yes & 1958 \\
\hline 10 & REVIEW OF ECONOMIC STUDIES & No & 1956 \\
\hline 11 & RAND J OURNAL OF ECONOMICS & No & 1984 \\
\hline 12 & J OURNAL OF MONETARY ECONOMICS & Yes & 1976 \\
\hline 13 & REVIEW OF FINANCIAL STUDIES & No & 1990 \\
\hline 14 & JOURNAL OF ECONOMETRICS & No & 1980 \\
\hline 15 & J OURNAL OF LABOR ECONOMICS & Yes & 1983 \\
\hline 16 & JOURNAL OF ECONOMIC GROWTH & Yes & 1999 \\
\hline 17 & REVIEW OF ECONOMICS \& STATISTICS & Yes & 1956 \\
\hline 18 & J OURNAL OF ECONOMIC THEORY & No & 1969 \\
\hline 19 & J OURNAL OF BUSINESS \& ECONOMIC STATISTICS & No & 1985 \\
\hline 20 & ECONOMICJ OURNAL & No & 1956 \\
\hline 21 & J OURNAL OF HUMAN RESOURCES & Yes & 1966 \\
\hline 22 & J OURNAL OF INTERNATIONAL ECONOMICS & No & 1971 \\
\hline 23 & J OURNAL OF PUBLIC ECONOMICS & No & 1976 \\
\hline 24 & INTERNATIONAL ECONOMIC REVIEW & Yes & 1960 \\
\hline 25 & J OURNAL OF APPLIED ECONOMETRICS & Yes & 1987 \\
\hline 26 & J OURNAL OF INDUSTRIAL ECONOMICS & No & 1956 \\
\hline 27 & J OURNAL OF MONEY CREDIT \& BANKING & Yes & 1976 \\
\hline 28 & GAMES \& ECONOMIC BEHAVIOR & Yes & 1991 \\
\hline 29 & ECONOMICTHEORY & No & 1995 \\
\hline 30 & REVIEW OF ECONOMIC DYNAMICS & No & 2001 \\
\hline
\end{tabular}




\section{Table 2: Summary statistics}

Articles per Journal Year is the number of articles a journal publishes in a given year. Number of Editors per Journal Year is the number of editors a journal has in a given year. Editor Tenure is the number of years an editor serves at a journal. Number of Editor Co-authors is the number of historical co-authors an editor has while serving as editor. Number of Authors per Article is the number of authors of a given article. Times Cited Count is the Web of Science count of the number of times an article has been cited in the Web of Science database. Same-J ournal Citations is the number of times a given article has been cited by a publication in the same journal. Self Citations is the number of times a given article has been cited by a publication with the same author(s). Colleague-Connected Article is a dummy variable which takes the value one if the article has an author at the same institution as the journal's editor. Co-author-Connected Article is a dummy variable which takes the value one if the article has an author which is a prior co-author of the editor. Any-Connected Article is the maximum of Colleague-Connected Article and Coauthor-Connected Article.

\begin{tabular}{|c|c|c|c|c|c|c|c|}
\hline & Mean & $\begin{array}{l}\text { Standard } \\
\text { Deviation }\end{array}$ & $\begin{array}{c}\text { 5th } \\
\text { Percentile }\end{array}$ & $\begin{array}{c}\text { 25th } \\
\text { Percentile }\end{array}$ & Median & $\begin{array}{c}\text { 75th } \\
\text { Percentile }\end{array}$ & $\begin{array}{c}\text { 95th } \\
\text { Percentile }\end{array}$ \\
\hline Articles per J ournal Year & 47.38 & 26.41 & 11 & 29 & 43 & 59 & 96 \\
\hline Number of Editors per J ournal Year & 3.42 & 2.37 & 1 & 1 & 3 & 5 & 8 \\
\hline Editor Tenure (years) & 6.13 & 5.18 & 1 & 3 & 5 & 7 & 16 \\
\hline Number of Editor Co-authors & 12.60 & 10.37 & 1 & 5 & 10 & 17 & 34 \\
\hline Number of Authors per Article & 1.66 & 0.78 & 1 & 1 & 2 & 2 & 3 \\
\hline Colleague-connected Article (Dummy) & 0.071 & 0.257 & 0 & 0 & 0 & 0 & 1 \\
\hline Co-author-connected Article (Dummy) & 0.032 & 0.176 & 0 & 0 & 0 & 0 & 0 \\
\hline Any-connected Article (Dummy) & 0.088 & 0.283 & 0 & 0 & 0 & 0 & 1 \\
\hline Times Cited Count & 32.95 & 105.47 & 0 & 3 & 10 & 30 & 125 \\
\hline Times Cited Count: Connected Articles & 51.55 & 164.81 & 0 & 4 & 15 & 45 & 190 \\
\hline Times Cited Count: Unconnected Articles & 31.15 & 97.68 & 0 & 3 & 10 & 29 & 119 \\
\hline Times Cited Count (Top 50 Schools) & 44.50 & 127.60 & 0 & 4 & 15 & 43 & 167 \\
\hline Same-J ournal Citations & 1.84 & 4.63 & 0 & 0 & 0 & 2 & 8 \\
\hline Self Citations & 1.07 & 2.04 & 0 & 0 & 0 & 1 & 5 \\
\hline Top 30 J ournal Citations & 9.11 & 24.19 & 0 & 0 & 2 & 9 & 38 \\
\hline
\end{tabular}




\section{Table 3: Editor-author connectivity and publication rates}

Each observation is a school, journal, year triplet $(i, j, t)$ that counts the number of publications school $i$ has in journal $\mathrm{j}$ in year $\mathrm{t}$. The top panel considers the 146 schools that, at any point, have had one or more editors at the 30 journals in Table 1. During Editorship is a dummy variable that takes the value of one if school $\mathrm{i}$ has an editor at journal $\mathrm{j}$ in year $\mathrm{t}-2$. Panel B considers the three finance journals (J ournal of Finance, J ournal of Financial Economics and Review of Financial Studies) and Panel C considers the top economics journals (AER, Journal of Political Economy, Econometrica, QJE and Review of Economic Studies). Robust standard errors clustered by school are in parentheses. *, **, and *** represent significance at the $10 \%, 5 \%$ and $1 \%$ levels, respectively.

\section{PANEL A: ALL JOURNALS}

Dependent Variable: Published Articles

\begin{tabular}{lcccc}
\hline During Editorship & $1.421^{* * *}$ & $1.427^{* * *}$ & $0.333^{* * *}$ & $0.297 * * *$ \\
& $(0.156)$ & $(0.154)$ & $(0.054)$ & $(0.050)$ \\
& & & & \\
& & & & YES \\
J ournal*Year Fixed Effects & NO & YES & YES \\
J ournal*School Fixed Effects & NO & NO & YES & YES \\
School*Year Fixed Effects & 163,520 & 163,520 & 163,520 & YES \\
Observations & 0.0376 & 0.1014 & 0.5053 & 0.5246 \\
Adjusted R & & & & \\
\hline
\end{tabular}

\section{PANEL B: FINANCE JOURNALS}

Dependent Variable: Published Articles

\begin{tabular}{lcccc}
\hline During Editorship & $\begin{array}{c}1.178^{* * *} \\
(0.205)\end{array}$ & $\begin{array}{c}1.349^{* * *} \\
(0.181)\end{array}$ & $\begin{array}{c}0.636^{* * *} \\
(0.154)\end{array}$ & $\begin{array}{c}0.609^{* * *} \\
(0.138)\end{array}$ \\
& & & & \\
& & & & YES \\
Journal*Year Fixed Effects & NO & YES & YES & YES \\
J ournal*School Fixed Effects & NO & NO & NOS & YES \\
School*Year Fixed Effects & 3,888 & 3,888 & 3,888 & 3,888 \\
Observations & 0.0224 & 0.1683 & 0.4687 & 0.5084 \\
Adjusted R & & & & \\
\hline \hline
\end{tabular}

\section{PANEL C: TOP ECONOMICS JOURNALS}

Dependent Variable: Published Articles

\begin{tabular}{lcccc}
\hline During Editorship & $2.433^{* * *}$ & $2.353^{* * *}$ & $0.291^{* *}$ & 0.183 \\
& $(0.5610)$ & $(0.5820)$ & $(0.1370)$ & $(0.1250)$ \\
& & & & \\
& NO & YES & YES & YES \\
Journal*Year Fixed Effects & NO & NO & YES & YES \\
J ournal*School Fixed Effects & NO & NO & NO & YES \\
School*Year Fixed Effects & 11,350 & 11,350 & 11,350 & 11,350 \\
Observations & 0.0589 & 0.1371 & 0.6572 & 0.6869 \\
Adjusted R & & & & \\
\hline
\end{tabular}




\section{Table 4: False editor matches and publication probabilities}

During Editorship is a dummy variable which takes the value of one if school $i$ has an editor at journal $j$ in year $\mathrm{t}-2$. J ust Before (J ust After) is a dummy variable that takes a value of one during the five years before (after) school i has an editor at journal $\mathrm{j}$. The first column of each panel presents the results from an OLS model, the second column from a Poisson count model, and the third column from a negative binomial count model. Panel A considers all journals. Panel B considers the three finance journals (J ournal of Finance, J ournal of Financial Economics and Review of Financial Studies) and Panel C considers the top economics journals (AER, Journal of Political Economy, Econometrica, QJE and Review of Economic Studies). *, **, and *** represent significance at the $10 \%, 5 \%$ and $1 \%$ levels, respectively.

PANEL A: ALL JOURNALS

Dependent Variable: Published Articles

\begin{tabular}{|c|c|c|c|}
\hline & OLS & POISSON & NEGATIVE BINOMIAL \\
\hline \multirow[t]{2}{*}{ During Editorship } & $1.439 * * *$ & $1.747 * * *$ & $1.752^{* * *}$ \\
\hline & $(0.157)$ & $(0.0150)$ & $(0.0390)$ \\
\hline \multirow[t]{2}{*}{ J ust Before } & $0.824^{* * *}$ & $1.195^{* * *}$ & $1.275^{* * *}$ \\
\hline & $(0.079)$ & $(0.0220)$ & $(0.0490)$ \\
\hline \multirow[t]{2}{*}{ Just After } & $0.797^{* * *}$ & $1.115^{* * *}$ & $1.229 * * *$ \\
\hline & $(0.096)$ & $(0.0240)$ & $(0.0550)$ \\
\hline Observations & 163,520 & 163,520 & 163,520 \\
\hline Adjusted $\mathrm{R}^{2}$ & 0.0536 & - & - \\
\hline Log likelihood & - & -138668.5 & -116615.2 \\
\hline p-value for test: During = Before & $<.001$ & $<.001$ & $<.001$ \\
\hline $\mathrm{p}$-value for test: During =After & $<001$ & $<.001$ & $<001$ \\
\hline p-value for test: Before $=$ After & 0.598 & 0.028 & 0.546 \\
\hline
\end{tabular}




\begin{tabular}{lccc}
\hline \hline & \multicolumn{3}{c}{ Dependent Variable: Published Articles } \\
& OLS & POISSON & NEGATIVE BINOMIAL \\
\hline During Editorship & $1.248^{* * *}$ & $0.693^{* * *}$ & $0.694^{* * *}$ \\
& $(0.226)$ & $(0.046)$ & $(0.090)$ \\
& & & \\
Just Before & 0.327 & $0.182^{* * *}$ & $0.195^{*}$ \\
& $(0.287)$ & $(0.061)$ & $(0.102)$ \\
& & & \\
Just After & $0.922^{* *}$ & $0.547^{* * *}$ & $0.552^{* * *}$ \\
& $(0.386)$ & $(0.051)$ & $(0.097)$ \\
& & & \\
Observations & 3,888 & 3,888 & - \\
Adjusted R & & - & -5869.5 \\
Loglikelihood & 0.0353 & -6803.9 & $<.001$ \\
& - & & 0.265 \\
p-value for test: During = Before & $<.001$ & $<.001$ & 0.009 \\
p-value for test: During =After & 0.197 & 0.026 & \\
p-value for test: Before =After & 0.010 & $<.001$ & \\
\end{tabular}

\section{PANEL C: TOP ECONOMICS JOURNALS}

\begin{tabular}{lccc}
\hline \hline & \multicolumn{3}{c}{ Dependent Variable: Published Articles } \\
& OLS & POISSON & NEGATIVE BINOMIAL \\
\hline During Editorship & $2.494^{* * *}$ & $1.409^{* * *}$ & $1.413^{* * *}$ \\
& $(0.5660)$ & $(0.027)$ & $(0.0820)$ \\
& & & \\
Just Before & $0.965^{* * *}$ & $0.721^{* * *}$ & $0.753^{* * *}$ \\
& $(0.2250)$ & $(0.040)$ & $(0.0960)$ \\
& & & \\
Just After & $0.911^{* *}$ & $0.673^{* * *}$ & $0.716^{* * *}$ \\
& $(0.2600)$ & $(0.043)$ & $(0.1030)$ \\
& & & \\
Observations & 11,350 & 11,350 & 11,350 \\
Adjusted R & & - & - \\
Log likelihood & 0.0739 & -19119.8 & -14324.7 \\
p-value for test: During = Before & - & & $<.001$ \\
p-value for test: During =After & $<.001$ & $<.001$ & $<001$ \\
p-value for test: Before =After & $<001$ & 0.463 & 0.799 \\
& 0.798 & & \\
\hline \hline
\end{tabular}




\section{Table 5: Editor-author connectivity and article quality}

Times Cited Count is the Web of Science count of the number of times an article has been cited in the Web of Science database. Log(Times Cited Count) is the natural logarithm of one plus Times Cited Count. Times Cited Count: Last 5 Years is the sum total of an author's citations over the prior five years (for articles with multiple authors the maximum is taken). Number of Authors is the number of authors of a given article. Colleague-Connected Article is a dummy variable which takes the value one if the article has an author at the same institution as the journal's editor. Co-author-Connected Article is a dummy variable which takes the value one if the article has an author which is a prior co-author of the editor. Any-Connected Article is the maximum of Colleague-Connected Article and Co-author-Connected Article. Panel A considers all 30 journals in Table 1. Panel B considers the three finance journals (J ournal of Finance, J ournal of Financial Economics and Review of Financial Studies) and Panel C considers the top economics journals (AER, J ournal of Political Economy, Econometrica, QJE and Review of Economic Studies). Robust standard errors are in parentheses. *, **, and *** represent significance at the $10 \%, 5 \%$ and $1 \%$ levels, respectively.

\section{PANEL A: ALL JOURNALS}

\section{Dependent Variable: Log(Times Cited Count)}

\begin{tabular}{|c|c|c|c|c|c|c|}
\hline Co-author-Connected Article & $\begin{array}{c}0.350 * * * \\
(0.044)\end{array}$ & & & & & \\
\hline Colleague-Connected Article & & $\begin{array}{c}0.425^{* * *} \\
(0.029)\end{array}$ & & & & \\
\hline Any-Connected Article & & & $\begin{array}{c}0.405^{* * *} \\
(0.026)\end{array}$ & $\begin{array}{c}0.250^{* * * *} \\
(0.019)\end{array}$ & $\begin{array}{l}0.043^{* *} \\
(0.020)\end{array}$ & $\begin{array}{l}0.089 * * \\
(0.036)\end{array}$ \\
\hline Times Cited Count: Last 5 Years & & & & $\begin{array}{c}0.114^{* * *} \\
(0.003)\end{array}$ & $\begin{array}{c}0.097 * * * \\
(0.003)\end{array}$ & $\begin{array}{c}0.040^{* * * *} \\
(0.011)\end{array}$ \\
\hline Number of Authors & & & & $\begin{array}{c}-0.046^{* * *} \\
(0.009)\end{array}$ & $\begin{array}{c}-0.028^{* * *} * \\
(0.009)\end{array}$ & $\begin{array}{l}0.046^{* *} \\
(0.021)\end{array}$ \\
\hline J ournal*Year Fixed Effects & NO & NO & NO & YES & YES & YES \\
\hline School Fixed Effects & NO & NO & NO & NO & YES & NO \\
\hline Author Fixed Effects & NO & NO & NO & NO & NO & YES \\
\hline Observations & 54,046 & 54,046 & 54,046 & 54,046 & 49,218 & 8,908 \\
\hline Adjusted R2 & 0.0013 & 0.0045 & 0.0052 & 0.3928 & 0.4157 & 0.6290 \\
\hline
\end{tabular}


Dependent Variable: Log(Times Cited Count)

\begin{tabular}{|c|c|c|c|c|c|c|}
\hline Co-author-Connected Article & $\begin{array}{c}0.821^{* * *} \\
(0.119)\end{array}$ & & & & & \\
\hline Colleague-Connected Article & & $\begin{array}{c}0.532^{* * *} \\
(0.085)\end{array}$ & & & & \\
\hline Any-Connected Article & & & $\begin{array}{c}0.580^{* * *} \\
(0.075)\end{array}$ & $\begin{array}{c}0.249 * * * \\
(0.052)\end{array}$ & $\begin{array}{c}0.079 \\
(0.057)\end{array}$ & $\begin{array}{l}0.190 * \\
(0.103)\end{array}$ \\
\hline Times Cited Count: Last 5 Years & & & & $\begin{array}{l}0.111^{* * *} \\
(0.007)\end{array}$ & $\begin{array}{c}0.082^{* * *} \\
(0.008)\end{array}$ & $\begin{array}{l}-0.003 \\
(0.033)\end{array}$ \\
\hline Number of Authors & & & & $\begin{array}{c}-0.079 * * * \\
(0.022)\end{array}$ & $\begin{array}{c}-0.047^{* *} \\
(0.023)\end{array}$ & $\begin{array}{c}0.018 \\
(0.058)\end{array}$ \\
\hline J ournal*Year Fixed Effects & NO & NO & NO & YES & YES & YES \\
\hline School Fixed Effects & NO & NO & NO & NO & YES & NO \\
\hline Author Fixed Effects & $\mathrm{NO}$ & NO & NO & $\mathrm{NO}$ & NO & YES \\
\hline Observations & 6,395 & 6,395 & 6,395 & 6,395 & 5,893 & 1,167 \\
\hline Adjusted R2 & 0.0071 & 0.0064 & 0.0099 & 0.5373 & 0.5219 & 0.6548 \\
\hline
\end{tabular}


PANEL C: TOP ECONOMICS JOURNALS

Dependent Variable: Log(Times Cited Count)

\begin{tabular}{|c|c|c|c|c|c|c|}
\hline Co-author-Connected Article & $\begin{array}{c}0.617 * * * \\
(0.086)\end{array}$ & & & & & \\
\hline Colleague-Connected Article & & $\begin{array}{c}0.537^{* * *} \\
(0.061)\end{array}$ & & & & \\
\hline Any-Connected Article & & & $\begin{array}{c}0.552^{* * *} \\
(0.052)\end{array}$ & $\begin{array}{c}0.311^{* * *} \\
(0.040)\end{array}$ & $\begin{array}{c}0.036 \\
(0.043)\end{array}$ & $\begin{array}{c}0.029 \\
(0.069)\end{array}$ \\
\hline Times Cited Count: Last 5 Years & & & & $\begin{array}{c}0.116 * * * \\
(0.007)\end{array}$ & $\begin{array}{c}0.093^{* * *} \\
(0.007)\end{array}$ & $\begin{array}{l}-0.014 \\
(0.020)\end{array}$ \\
\hline Number of Authors & & & & $\begin{array}{c}-0.049 * * \\
(0.022)\end{array}$ & $\begin{array}{l}-0.021 \\
(0.023)\end{array}$ & $\begin{array}{c}0.067 \\
(0.043)\end{array}$ \\
\hline J ournal*Year Fixed Effects & NO & NO & NO & YES & YES & YES \\
\hline School Fixed Effects & NO & NO & NO & NO & YES & NO \\
\hline Author Fixed Effects & NO & NO & $\mathrm{NO}$ & NO & NO & YES \\
\hline Observations & 15871 & 15871 & 15871 & 15871 & 13311 & 2854 \\
\hline Adjusted R2 & 0.0030 & 0.0055 & 0.0075 & 0.3149 & 0.3356 & 0.6297 \\
\hline
\end{tabular}




\section{Table 6: Editor-author connectivity, article placement and citations}

Times Cited Count is the Web of Science count of the number of times an article has been cited in the Web of Science database. Log(Times Cited Count) is the natural logarithm of one plus Times Cited Count. Times Cited Count: Last 5 Years is the sum total of an author's citations over the prior five years (for articles with multiple authors the maximum is taken). Number of Authors is the number of authors of a given article. Colleague-Connected Article is a dummy variable which takes the value one if the article has an author at the same institution as the journal's editor. Co-author-Connected Article is a dummy variable which takes the value one if the article has an author which is a prior co-author of the editor. Any-Connected Article is the maximum of Colleague-Connected Article and Co-author-Connected Article. Lead Article is a dummy variable which takes the value of one if an article is first in an issue. Second Article and Third Article are similarly defined. Same Issue as Star Article is a dummy variable which takes the value of one if a paper is in the same issue as the a lead article with the most cite counts during the journal year. Robust standard errors are in parentheses. *, **, and ${ }^{* * *}$ represent significance at the $10 \%, 5 \%$ and $1 \%$ levels, respectively.

PANEL A: PLACEMENT AND CITATIONS

Dependent Variable: Log(Times Cited Count)

\begin{tabular}{|c|c|c|c|c|}
\hline Lead Article & $\begin{array}{c}0.536 * * * \\
(0.018)\end{array}$ & & & \\
\hline Second Article & & $\begin{array}{c}0.263^{* * * *} \\
(0.018)\end{array}$ & & \\
\hline Third Article & & & $\begin{array}{c}0.167 * * * \\
(0.018)\end{array}$ & \\
\hline Same Issue as Star Article & & & & $\begin{array}{c}0.079 * * * \\
(0.014)\end{array}$ \\
\hline Times Cited Count: Last 5 Years & $\begin{array}{l}0.113^{* * *} \\
(0.003)\end{array}$ & $\begin{array}{l}0.117 * * * \\
(0.003)\end{array}$ & $\begin{array}{l}0.119 * * * \\
(0.003)\end{array}$ & $\begin{array}{l}0.116 * * * \\
(0.003)\end{array}$ \\
\hline Number of Authors & $\begin{array}{c}-0.042^{* * *} \\
(0.009)\end{array}$ & $\begin{array}{c}-0.046^{* * *} \\
(0.009)\end{array}$ & $\begin{array}{c}-0.048^{* * *} \\
(0.009)\end{array}$ & $\begin{array}{c}-0.042^{* * *} \\
(0.010)\end{array}$ \\
\hline $\begin{array}{l}\text { J ournal*Year Fixed Effects } \\
\text { Observations } \\
\text { Adjusted } R^{2}\end{array}$ & $\begin{array}{c}\text { YES } \\
54,046 \\
0.3883\end{array}$ & $\begin{array}{c}\text { YES } \\
54,046 \\
0.3803\end{array}$ & $\begin{array}{c}\text { YES } \\
54,046 \\
0.3788\end{array}$ & $\begin{array}{c}\text { YES } \\
48,638 \\
0.3769\end{array}$ \\
\hline
\end{tabular}


PANEL B: CONNECTIVITY AND PLACEMENT

\begin{tabular}{|c|c|c|c|c|c|c|c|c|}
\hline & \multicolumn{4}{|c|}{ Dependent Variable: Lead Article (Dummy) } & \multicolumn{4}{|c|}{ Dependent Variable: In Star Issue (Dummy) } \\
\hline Co-author-Connected Article & $\begin{array}{c}0.069 \text { *** } \\
(0.010)\end{array}$ & & & & $\begin{array}{c}0.060 \text { *** } \\
(0.015)\end{array}$ & & & \\
\hline Colleague-Connected Article & & $\begin{array}{c}0.055^{* * *} \\
(0.006)\end{array}$ & & & & $\begin{array}{c}0.025^{* * *} \\
(0.009)\end{array}$ & & \\
\hline Any-Connected Article & & & $\begin{array}{c}0.057^{* * *} \\
(0.006)\end{array}$ & $\begin{array}{c}0.055^{* * *} \\
(0.006)\end{array}$ & & & $\begin{array}{c}0.029 * * * \\
(0.008)\end{array}$ & $\begin{array}{c}0.010 \\
(0.007)\end{array}$ \\
\hline Times Cited Count: Last 5 Years & & & & $\begin{array}{c}0.009 * * * \\
(0.001)\end{array}$ & & & & $\begin{array}{l}0.0004 \\
(0.001)\end{array}$ \\
\hline Number of Authors & & & & $\begin{array}{c}-0.011^{* * *} \\
(0.002)\end{array}$ & & & & $\begin{array}{c}0.002 \\
(0.003)\end{array}$ \\
\hline J ournal*Year Fixed Effects & NO & NO & NO & YES & NO & NO & NO & YES \\
\hline Observations & 54,046 & 54,046 & 54,046 & 54,046 & 48,638 & 48,638 & 48,638 & 48,638 \\
\hline Adjusted R2 & 0.0012 & 0.0020 & 0.0028 & 0.0112 & 0.0003 & 0.0001 & 0.0003 & 0.2286 \\
\hline
\end{tabular}




\section{Table 7: Citations influences by editors or authors}

Times Cited Count is the Web of Science count of the number of times an article has been cited in the Web of Science database. Log(Times Cited Count) is the natural logarithm of one plus Times Cited Count. Times Cited Count: Last 5 Years is the sum total of an author's citations over the prior five years (for articles with multiple authors the maximum is taken). Number of Authors is the number of authors of a given article. Colleague-Connected Article is a dummy variable which takes the value one if the article has an author at the same institution as the journal's editor. Co-author-Connected Article is a dummy variable which takes the value one if the article has an author which is a prior co-author of the editor. Any-Connected Article is the maximum of Colleague-Connected Article and Co-author-Connected Article. The first three columns exclude from Times Cited Count citations which come from the same journal (e.g. QJ E articles citing QJ E articles). The final three columns exclude from Times Cited Count citations which come from the same author(s). Panel A considers all 30 journals in Table 1. Panel B considers the three finance journals (J ournal of Finance, J ournal of Financial Economics and Review of Financial Studies) and Panel C considers the top economics journals (AER, J ournal of Political Economy, Econometrica, QJ E and Review of Economic Studies). Robust standard errors are in parentheses. *, **, and *** represent significance at the $10 \%, 5 \%$ and $1 \%$ levels, respectively.

\section{PANEL A: ALL JOURNALS}

\section{Dependent Variable: Log(Times Cited Count)}

EXCLUDING SAME J OURNAL CITATIONS

\begin{tabular}{|c|c|c|c|c|c|c|}
\hline & \multicolumn{3}{|c|}{ EXCLUDING SAME J OURNAL CITATIONS } & \multicolumn{3}{|c|}{ EXCLUDING SELF CITATIONS } \\
\hline Any-Connected Article & $\begin{array}{c}0.227 * * * \\
(0.018)\end{array}$ & $\begin{array}{c}0.033^{*} \\
(0.019)\end{array}$ & $\begin{array}{l}0.078^{* *} \\
(0.034)\end{array}$ & $\begin{array}{c}0.243^{* * *} \\
(0.018)\end{array}$ & $\begin{array}{c}0.042^{* *} \\
(0.019)\end{array}$ & $\begin{array}{l}0.086^{* *} \\
(0.034)\end{array}$ \\
\hline Times Cited Count: Last 5 Years & $\begin{array}{c}0.106^{* * *} \\
(0.003)\end{array}$ & $\begin{array}{c}0.090^{* * *} \\
(0.003)\end{array}$ & $\begin{array}{c}0.039 * * * \\
(0.011)\end{array}$ & $\begin{array}{c}0.106^{* * *} \\
(0.003)\end{array}$ & $\begin{array}{c}0.089^{* * * *} \\
(0.003)\end{array}$ & $\begin{array}{c}0.042^{* * *} \\
(0.011)\end{array}$ \\
\hline Number of Authors & $\begin{array}{c}-0.038 * * * \\
(0.009)\end{array}$ & $\begin{array}{c}-0.022^{* *} \\
(0.009)\end{array}$ & $\begin{array}{l}0.046^{* *} \\
(0.020)\end{array}$ & $\begin{array}{c}-0.049 * * * \\
(0.009)\end{array}$ & $\begin{array}{c}-0.032 * * * \\
(0.009)\end{array}$ & $\begin{array}{c}0.034^{*} \\
(0.020)\end{array}$ \\
\hline J ournal*Year Fixed Effects & YES & YES & YES & YES & YES & YES \\
\hline School Fixed Effects & NO & YES & NO & NO & YES & NO \\
\hline Author Fixed Effects & NO & NO & YES & NO & NO & YES \\
\hline Observations & 53,864 & 49,077 & 8,891 & 53,981 & 49,160 & 8,898 \\
\hline Adjusted R² & 0.3879 & 0.4119 & 0.5583 & 0.3833 & 0.4088 & 0.5542 \\
\hline
\end{tabular}


PANEL B: FINANCE JOURNALS

Dependent Variable: Log(Times Cited Count)

\begin{tabular}{|c|c|c|c|c|c|c|}
\hline & \multicolumn{3}{|c|}{ EXCLUDING SAME J OURNAL CITATIONS } & \multicolumn{3}{|c|}{ EXCLUDING SELF CITATIONS } \\
\hline Any-Connected Article & $\begin{array}{c}0.236 * * * \\
(0.048)\end{array}$ & $\begin{array}{c}0.080 \\
(0.053)\end{array}$ & $\begin{array}{c}0.184^{*} \\
(0.097)\end{array}$ & $\begin{array}{c}0.244^{* * *} \\
(0.049)\end{array}$ & $\begin{array}{c}0.081 \\
(0.054)\end{array}$ & $\begin{array}{l}0.202^{* *} \\
(0.098)\end{array}$ \\
\hline Times Cited Count: Last 5 Years & $\begin{array}{c}0.0100 * * * \\
(0.007)\end{array}$ & $\begin{array}{c}0.075^{* * *} \\
(0.008)\end{array}$ & $\begin{array}{l}-0.001 \\
(0.032)\end{array}$ & $\begin{array}{c}0.0103^{* * * *} \\
(0.008)\end{array}$ & $\begin{array}{c}0.077 * * * \\
(0.008)\end{array}$ & $\begin{array}{l}-0.002 \\
(0.032)\end{array}$ \\
\hline Number of Authors & $\begin{array}{c}-0.066^{* * *} \\
(0.021)\end{array}$ & $\begin{array}{c}-0.039 * \\
(0.021)\end{array}$ & $\begin{array}{c}0.008 \\
(0.055)\end{array}$ & $\begin{array}{c}-0.076^{* * *} \\
(0.021)\end{array}$ & $\begin{array}{c}-0.049 * * \\
(0.021)\end{array}$ & $\begin{array}{c}0.001 \\
(0.055)\end{array}$ \\
\hline J ournal*Year Fixed Effects & YES & YES & YES & YES & YES & YES \\
\hline School Fixed Effects & NO & YES & NO & NO & YES & NO \\
\hline Author Fixed Effects & NO & NO & YES & NO & NO & YES \\
\hline Observations & 6,381 & 5,879 & 1,165 & 6,393 & 5,891 & 1,167 \\
\hline Adjusted R² & 0.5396 & 0.5237 & 0.6409 & 0.5347 & 0.5204 & 0.6420 \\
\hline
\end{tabular}

\section{PANEL C: TOP ECONOMICS JOURNALS}

\section{Dependent Variable: Log(Times Cited Count)}

\begin{tabular}{|c|c|c|c|c|c|c|}
\hline & \multicolumn{3}{|c|}{ EXCLUDING SAME J OURNAL CITATIONS } & \multicolumn{3}{|c|}{ EXCLUDING SELF CITATIONS } \\
\hline Any-Connected Article & $\begin{array}{c}0.307^{* * *} \\
(0.034)\end{array}$ & $\begin{array}{c}0.054 \\
(0.036)\end{array}$ & $\begin{array}{c}0.100 \\
(0.063)\end{array}$ & $\begin{array}{c}0.304^{* * *} \\
(0.035)\end{array}$ & $\begin{array}{c}0.045 \\
(0.037)\end{array}$ & $\begin{array}{c}0.087 \\
(0.066)\end{array}$ \\
\hline Times Cited Count: Last 5 Years & $\begin{array}{c}0.110^{* * * *} \\
(0.007)\end{array}$ & $\begin{array}{c}0.088^{* * * *} \\
(0.007)\end{array}$ & $\begin{array}{c}-0.018 \\
(0.019)\end{array}$ & $\begin{array}{c}0.110^{* * *} \\
(0.007)\end{array}$ & $\begin{array}{c}0.088 * * * \\
(0.007)\end{array}$ & $\begin{array}{r}-0.013 \\
(0.019)\end{array}$ \\
\hline Number of Authors & $\begin{array}{c}-0.043^{* *} \\
(0.021)\end{array}$ & $\begin{array}{c}-0.019 \\
(0.022)\end{array}$ & $\begin{array}{c}0.071^{*} \\
(0.040)\end{array}$ & $\begin{array}{c}-0.055^{* * *} \\
(0.021)\end{array}$ & $\begin{array}{c}-0.030 \\
(0.022)\end{array}$ & $\begin{array}{c}0.045 \\
(0.042)\end{array}$ \\
\hline J ournal*Year Fixed Effects & YES & YES & YES & YES & YES & YES \\
\hline School Fixed Effects & NO & YES & NO & NO & YES & NO \\
\hline Author Fixed Effects & NO & $\mathrm{NO}$ & YES & NO & NO & YES \\
\hline Observations & 15779 & 13253 & 2833 & 15852 & 13297 & 2838 \\
\hline Adjusted R ${ }^{2}$ & 0.322 & 0.344 & 0.6342 & 0.3116 & 0.3358 & 0.6243 \\
\hline
\end{tabular}




\section{Table 8: Productivity in Other J ournals}

Each observation is a school, journal, year triplet $(i, j, t)$ that counts the number of publications school $i$ has in journal $\mathrm{j}$ in year $\mathrm{t}-2$. During Editorship is a dummy variable which takes the value of one for observation ( $\mathrm{i}, \mathrm{j}, \mathrm{t}$ ) if school $\mathrm{i}$ has an editor at a finance journal other than $\mathrm{j}$ in year $\mathrm{t}-2$. J ust Before (J ust After) is a dummy variable that takes a value of one during the five years before (after) school $i$ has an editor at a finance journal other than $\mathrm{j}$. The first column presents the results from an OLS model, the second column from a Poisson count model, and the third column from a negative binomial count model. $*, * *$, and $* * *$ represent significance at the $10 \%, 5 \%$ and $1 \%$ levels, respectively.

\section{FINANCE JOURNALS}

Dependent Variable: Published Articles

\begin{tabular}{lccc} 
& OLS & POISSON & $\begin{array}{c}\text { NEGATIVE } \\
\text { BINOMIAL }\end{array}$ \\
\hline During Editorship & $0.337^{* * *}$ & $0.269^{* * *}$ & $0.232^{* * *}$ \\
& $(0.099)$ & $(0.047)$ & $(0.075)$ \\
Just Before & & & $0.241^{* * *}$ \\
& $0.351^{* * *}$ & $0.237^{* * *}$ & $(0.079)$ \\
& $(0.1080)$ & $(0.045)$ & $0.276^{* * *}$ \\
Just After & $0.405^{* * *}$ & & $(0.083)$ \\
& $(0.134)$ & $0.269^{* * *}$ & \\
& & $(0.047)$ & 3,888 \\
Observations & 3,888 & & - \\
Adjusted R & & & -5901.6 \\
Log likelihood & 0.008 & 3,888 & 0.930 \\
& - & -6902.4 & 0.683 \\
p-value for test: During = Before & 0.925 & 0.911 & 0.756 \\
p-value for test: During =After & 0.681 & 0.530 & \\
p-value for test: Before =After & 0.752 & 0.617 & \\
\hline \hline
\end{tabular}




\section{Table 9: Robustness}

Panel A replicates the first column of Table 4 (Panel A) but changes the delay between editorship and publication. Column 1 assumes a one year delay. Column 2 assumes a three year delay. Column 3 follows the publication trends found in Ellison (2002) and uses a one year delay for all publications before 1970, a two delay for papers between 1970 and 1995 and a three year delay for papers after 1995. Panel B replicates the final columns of Table 5 (Panel A) with a robust set of citation measures. The first three columns only consider citations received from journals on the list in Table 1. The final three columns winsorize the dependent variable (logged citations) at the $1 \%$ level. *, **, and *** represent significance at the $10 \%, 5 \%$ and $1 \%$ levels, respectively.

\section{PANEL A: PUBLICATION COUNTS}

Dependent Variable: Published Articles

\begin{tabular}{|c|c|c|c|}
\hline & 1-Year Publication Lag & 3-Year Publication Lag & Ellison Publication Lag \\
\hline During Editorship & $\begin{array}{l}1.443^{* * *} \\
(0.1540)\end{array}$ & $\begin{array}{c}1.453 * * * \\
(0.163)\end{array}$ & $\begin{array}{c}1.451^{* * *} \\
(0.162)\end{array}$ \\
\hline J ust Before & $\begin{array}{l}0.769 * * * \\
(0.0750)\end{array}$ & $\begin{array}{c}0.837 * * * \\
(0.079)\end{array}$ & $\begin{array}{c}0.813^{* * *} \\
(0.077)\end{array}$ \\
\hline J ust After & $\begin{array}{l}0.824^{* * *} \\
(0.1010)\end{array}$ & $\begin{array}{c}0.760 * * * \\
(0.097)\end{array}$ & $\begin{array}{c}0.774^{* * * *} \\
(0.094)\end{array}$ \\
\hline $\begin{array}{l}\text { Observations } \\
\text { Adjusted } \mathrm{R}^{2}\end{array}$ & $\begin{array}{c}163,520 \\
0.0548\end{array}$ & $\begin{array}{l}163,520 \\
0.0522\end{array}$ & $\begin{array}{l}163,520 \\
0.0523\end{array}$ \\
\hline $\begin{array}{l}\text { p-value for test: } \text { During }=\text { Before } \\
\text { p-value for test: } \text { During }=\text { After } \\
\text { p-value for test: Before }=\text { After }\end{array}$ & $\begin{array}{l}<.001 \\
<001 \\
0.411\end{array}$ & $\begin{array}{l}<.001 \\
<.001 \\
0.269\end{array}$ & $\begin{array}{l}<.001 \\
<001 \\
0.564\end{array}$ \\
\hline
\end{tabular}




\section{Dependent Variable: Log(Times Cited Count)}

\begin{tabular}{|c|c|c|c|c|c|c|}
\hline \multirow{3}{*}{ Any-Connected Article } & \multicolumn{3}{|c|}{ ONLY CITATIONS FROM TOP J OURNALS } & \multicolumn{3}{|c|}{ WINSORIZED CITATIONS } \\
\hline & $0.250 * * *$ & $0.055^{* * *}$ & $0.098^{* * *}$ & $0.240^{* * *}$ & $0.041^{* *}$ & 0.069* \\
\hline & -0.016 & -0.017 & -0.03 & $(0.020)$ & $(0.021)$ & $(0.036)$ \\
\hline \multirow[t]{2}{*}{ Times Cited Count: Last 5 Years } & $0.105^{* * *}$ & $0.089 * * *$ & $0.027^{* * *}$ & $0.113^{* * *}$ & $0.096^{* * *}$ & $0.041^{* * *}$ \\
\hline & -0.003 & -0.003 & -0.01 & $(0.003)$ & $(0.003)$ & $(0.011)$ \\
\hline \multirow[t]{2}{*}{ Number of Authors } & $-0.120^{* * *}$ & $-0.099 * * *$ & 0.013 & $-0.044^{* * *}$ & $-0.027 * * *$ & $0.043^{* *}$ \\
\hline & -0.008 & -0.008 & -0.017 & $(0.009)$ & $(0.009)$ & $(0.021)$ \\
\hline J ournal*Year Fixed Effects & YES & YES & YES & YES & YES & YES \\
\hline School Fixed Effects & NO & YES & NO & NO & YES & NO \\
\hline Author Fixed Effects & $\mathrm{NO}$ & NO & YES & $\mathrm{NO}$ & NO & YES \\
\hline Observations & 54,046 & 49,218 & 8,908 & 54046 & 49218 & 8908 \\
\hline Adjusted $\mathrm{R}^{2}$ & 0.3439 & 0.3755 & 0.5328 & 0.3955 & 0.4178 & 0.6312 \\
\hline
\end{tabular}

